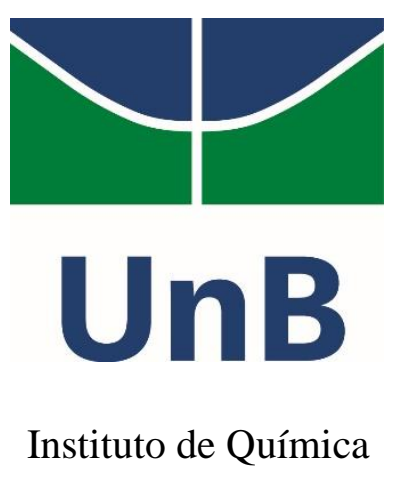

Programa de Pós-Graduação em Química

DISSERTAÇÃO DE MESTRADO

\title{
PROPRIEDADES ÓPTICAS DE C-DOTS PRODUZIDOS A PARTIR DE RESÍDUOS DA INDÚSTRIA CERVEJEIRA
}

Carime Vitória da Silva Rodrigues

Orientador: Marcelo Oliveira Rodrigues

Coorientadora: Raimunda Nonata Ribeiro Sampaio

Brasília, DF 

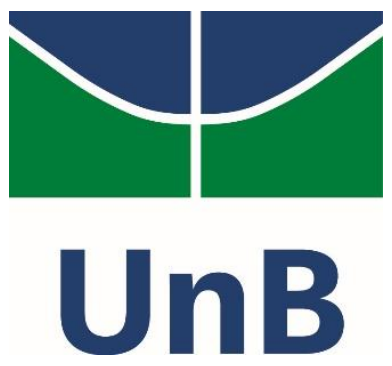

Instituto de Química

Programa de Pós-Graduação em Química

DISSERTAÇÃO DE MESTRADO

\section{PROPRIEDADES ÓPTICAS DE C-DOTS PRODUZIDOS A PARTIR DE RESÍDUOS DA INDÚSTRIA CERVEJEIRA}

Dissertação apresentada ao Instituto de Química da Universidade de Brasília, como requisito parcial para obtenção do título de Mestre em Química.

Carime Vitória da Silva Rodrigues

Orientador: Marcelo Oliveira Rodrigues

Coorientadora: Raimunda Nonata Ribeiro Sampaio

Brasília, DF 
Dedicatória

Dedico este trabalho à minha família e amigos.

"O homem nunca sabe do que é capaz, até que o tenta."

Charles Dickens 


\section{Agradecimentos}

A Deus, pela força e saúde para superar os desafios diários;

A minha família, pelo apoio, carinho e cuidado constantes;

A meu namorado, Pedro, por ter acompanhado meu trabalho de perto, incentivandome a não desistir diante de resultados negativos;

A meus amigos, pelos momentos de descontração;

Especialmente, a meu orientador, Prof. Dr. Marcelo Oliveira Rodrigues, por todo o conhecimento, pela orientação cuidadosa, e também pela amizade e compreensão;

A Prof ${ }^{a}$. Dra ${ }^{a}$ Raimunda Nonata Ribeiro Sampaio, pela coorientação;

A todos os colegas do LIMA, pela amizade e ajuda;

Aos Professores Dr. Brenno Amaro da Silveira Neto, Dr. Juliano Alexandre Chaker, Drª . Ingrid Távora Weber e Drª . Marly Eiko Osugi por terem contribuído para minha formação;

Aos professores Dr. José Raimundo Correa e Dr. Jorlandio Francisco Felix e seus grupos, pela cooperação;

Aos amigos que ajudaram em certas análises, Gabriel, Haline e Jefferson;

Ao Prof. Dr. Peter, que fez a revisão minuciosa de nosso artigo;

A todos os funcionários e colegas do IQ que tornaram o trabalho mais leve com suas simpatias e gentilezas.

À UnB, pela oportunidade de fazer um mestrado, a CAPES, pela bolsa de estudos e a FAP-DF e DPP-UnB, por terem contribuído para o financiamento de minha pesquisa;

Aos professores da banca por terem aceitado o convite;

E a todos os que contribuíram de alguma maneira para este trabalho;

MUITO OBRIGADA! 


\section{Resumo}

Procedimentos sintéticos simples foram aplicados para a obtenção de Quantum Dots de Carbono altamente luminescentes, também conhecidos como C-Dots, a partir de uma fonte de carbono abundante, que são os resíduos da indústria cervejeira. Os procedimentos sintéticos foram realizados com o objetivo de investigar os efeitos da etapa de oxidação sobre as propriedades do nanomaterial. As propriedades de Downconversion e Upconversion dos CDots são aqui exploradas. Além disso, os C-Dots foram aplicados em experimentos de imageamento em células e vivas e fixadas e os resultados são aqui discutidos.

Palavras-chave: Quantum Dots de Carbono (C-Dots), Luminescência, Upconversion. 


\begin{abstract}
Simple synthetic procedures have been applied for obtaining highly luminescent carbon quantum dots, also referred to as C-Dots, from an abundant carbon source, which are the brewing industry waste. The synthetic procedures have been conducted aiming at investigating the effects of the oxidation stage on the properties of the nanomaterial. C-Dots down- and up-conversion properties are disclosed herein. Besides, those C-Dots were applied in cellular imaging experiments in live and adhered cells and the results are disclosed herein.
\end{abstract}

Keywords: Carbon quantum dots (C-dots), Luminescence, Up-conversion. 


\section{Sumário}

Índice de Figuras …................................................................................................ vii

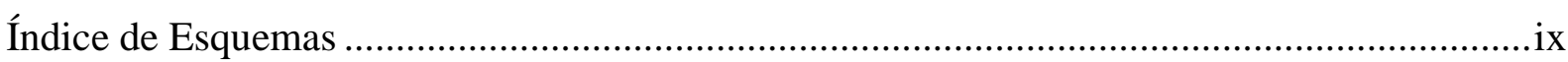

Lista de Abreviaturas e Acrônimos .........................................................................................

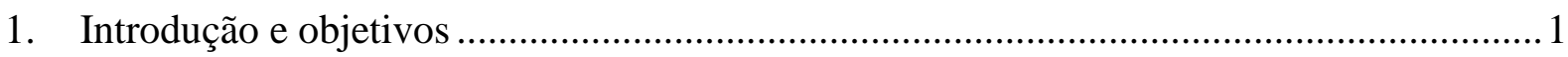

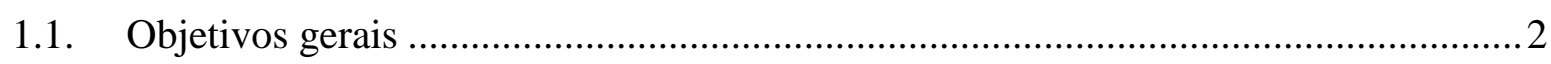

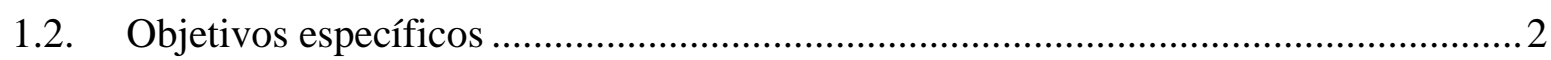

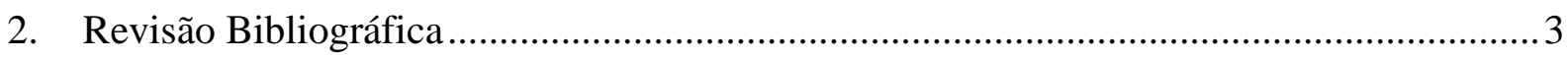

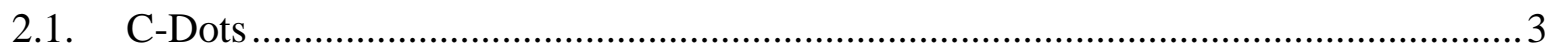

2.1.1. Fontes de Carbono e Métodos de Síntese ...............................................................

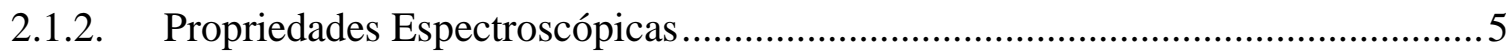

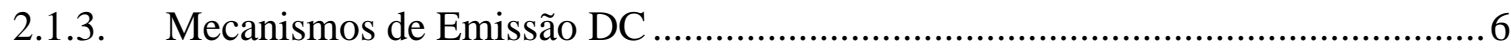

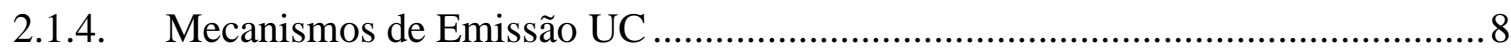

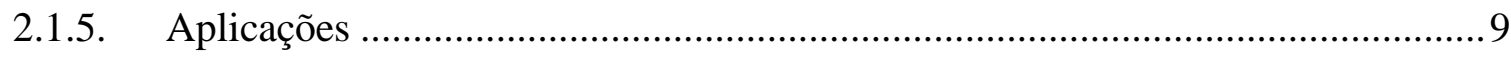

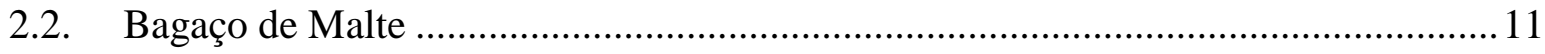

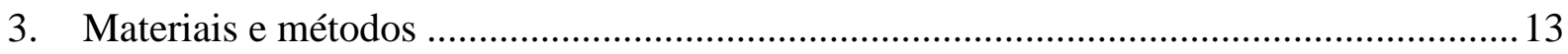

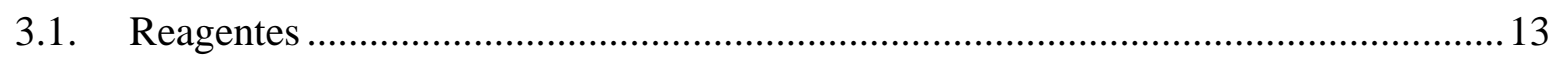

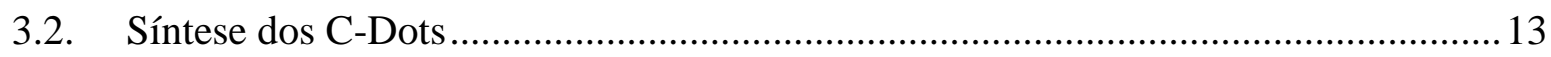

3.3. Experimentos de Imageamento Celular ........................................................ 14

3.4. Métodos de caracterização ........................................................................ 15

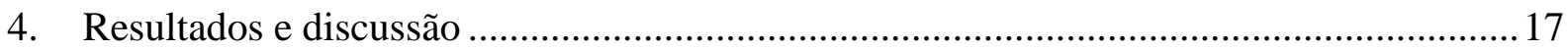

4.1. Comparação entre C-Dots produzidos através de diferentes rotas sintéticas .............17

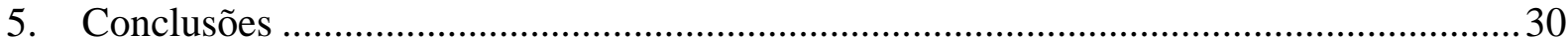

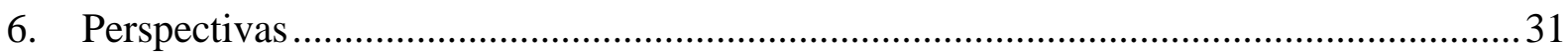

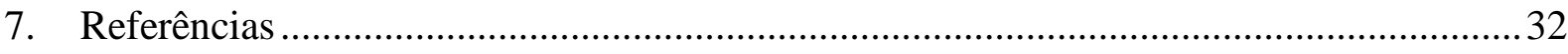

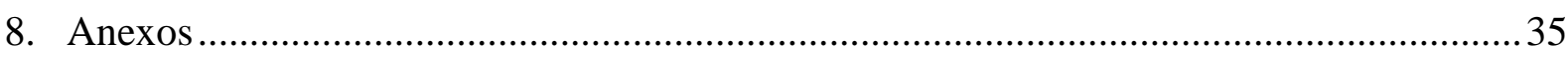




\section{Índice de Figuras}

Figura 1- Descobertas das novas formas alotrópicas do carbono ao longo do tempo. As imagens das estruturas foram retiradas da referência 4

Figura 2- Fontes não convencionais (casca de melancia, estrume de ruminantes e cabelo) resultando em partículas de natureza grafítica como aquela cuja imagem de MET encontra-se nesta figura, com tamanhos abaixo de $10 \mathrm{~nm}$, e através de métodos físicos ou químicos.

Figura 3- (a) espectros de emissão de C-Dots com máximos de intensidade dependentes do comprimento de onda de excitação. Imagens de C-Dots de diferentes tamanhos sob excitação de $365 \mathrm{~nm}$ no fundo. (b) C-Dots sob diferentes comprimentos de onda de excitação

Figura 4- (a) passivação da superfície dos C-Dots (referência 27) (b) mecanismos de emissão dos C-Dots (referência 6).

Figura 5- Alguns dos mecanismos responsáveis pelas emissões dos C-Dots, de acordo com classificação adotada por alguns autores.

Figura 6- Mecanismos de UC: (a) emissões anti-Stokes (referência 39); (b) por absorção de dois fótons (referência 42).

Figura 7- Ilustrações e experimentos de algumas das aplicações em meio biológico dos C-

Dots: (a) sondas fluorescentes, referência 49; (b) carreamento de fármacos usados no tratamento contra o câncer, referência 51; (c) imagens de fluorescência in vivo NIR em tempo real após a injeção intravenosa de C-Dots em ratinhos nus, em diferentes pontos temporais, referência 48; (d) imagem de luminescência de dois fótons $\left(\lambda_{\mathrm{ex}}=800 \mathrm{~nm}\right) \mathrm{de}$ células humanas de câncer de mama MCF-7, referência 24.

Figura 8- Fluxograma de uma indústria cervejeira e a geração de resíduos. Figura adaptada da referência 57.

Figura 9- Ilustrações dos C-Dots 1 e 2. 18

Figura 10- (a) e (b): imagens de MET dos C-Dots 1 e 2. (c) e (f): zoom das regiões marcadas das figuras (a) e (b), respectivamente, enfatizando os parâmetros de rede de partículas representativas. (d) e (e): histogramas de distribuição de tamanho de $\mathbf{1}$ e $\mathbf{2}$ 19

Figura 11- Espectros de IV dos materiais. As curvas em preto e vermelho referem-se às amostras 1 e 2 , respectivamente. 20

Figura 12- Espectro de Raman dos C-Dots 1. C-Dots 2 apresentaram perfil idêntico............. 21 
Figura 13- Espectros de absorção no UV-Vis e de emissão dos C-Dots. As linhas em vermelho e preto referem-se a $\mathbf{1}$ e $\mathbf{2}$, respectivamente. Os espectros de emissão foram adquiridos a temperatura ambiente, sob excitação de $300 \mathrm{~nm}$. As setas preta e vermelha indicam as transições $n-\pi^{*}$ e $\pi-\pi^{*}$. A figura anexa mostra 1 sob luz ultravioleta $\left(\lambda_{\text {ex }}=366\right.$ $\mathrm{nm})$.

Figura 14- (a) Curvas obtidas a partir do método de Tauc para 1 e 2. As linhas em vermelho e preto referem-se a 1 e $\mathbf{2}$, respectivamente. (b) Ilustração dos gaps de energia dos materiais 23

Figura 15- (a) e (c): espectros de emissão de 1 e $\mathbf{2}$ adquiridos a temperatura ambiente sob comprimentos de onda de excitação progressivamente maiores (de $300 \mathrm{~nm}$ a $450 \mathrm{~nm}$ ); (b) e (d): intensidades de emissão em função do comprimento de onda de excitação de $\mathbf{1}$ e $\mathbf{2}$.

Figura 16- (a) e (b): intensidades de emissão em função do pH de 1 e 2, sob excitação de 300 $\mathrm{nm}$

Figura 17- (a) e (b): intensidades de emissão em função da temperatura das soluções de $\mathbf{1}$ e $\mathbf{2}$, sob excitação de $300 \mathrm{~nm}$.

Figura 18- Espectros de excitação de $\mathbf{1}$ e $\mathbf{2}$ na região do NIR, adquiridos a temperatura ambiente, monitorando suas emissões em $460 \mathrm{~nm}$.

Figura 19-(a) e (b): espectros de emissão de UC de 1 e 2, a temperatura ambiente, $\mathrm{pH}=6$, sob excitação na região do NIR

Figura 20- Experimentos de bioimageamento usando os C-dots 1 em células MCF-7 $\left(\lambda_{\text {ex }}=405\right.$ nm). (a) e (b) mostram os padrões de coloração (verde) para células fixadas e vivas, respectivamente. (c) e (d) exibem a sobreposição entre 1 e a coloração do DNA com DAPI. C-Dots 1 e DAPI são responsáveis pelas emissões verde $\left(\lambda_{\mathrm{em}}=495 \mathrm{~nm}\right)$ e azul, respectivamente. Barras de referência: $10 \mu \mathrm{m}$ para (a) e (c) e $25 \mu \mathrm{m}$ para (b) e (d). 28 


\section{Índice de Esquemas}

Esquema 1- Resumo dos procedimentos sintéticos utilizados para a obtenção dos C-Dots 1 e 2 14 


\section{Lista de Abreviaturas e Acrônimos}

AnB-

Anfotericina B

C-Dots

Quantum dots de carbono

DAPI

4',6-diamidino-2-fenilindol

$\mathrm{DC}$ Downconversion

DNA

Ácido desoxirribonucleico

IV

Espectroscopia na região do infravermelho

MCF-7 Células de câncer de mama

MET Microscopia eletrônica de transição de alta resolução

NIR Infravermelho próximo

PBS Solução tampão fosfato salino

$\mathrm{UC}$ Upconversion

UV Ultravioleta

UV-Vis Espectroscopia na região do ultravioleta-visível 


\section{Introdução e objetivos}

Os atos de produzir novas tecnologias de maneira sustentável, de tornar os processos já existentes, também, sustentáveis e de buscar adventos que possam vir a melhorar a vida do ser humano são uma obrigação para todos aqueles envolvidos no mundo científico. Este trabalho foi realizado sob a luz deste compromisso, e tendo em mente os propósitos da chamada Nanotecnologia Verde. Essa abordagem da nanotecnologia surgiu com a necessidade de produzir de forma ambientalmente sustentável e tem seus princípios embasados em três propósitos suplementares entre si: a concepção de tecnologias limpas baseadas em nanotecnologia; a minimização dos riscos ambientais e à saúde humana que podem estar associados à nanotecnologia; e o incentivo à substituição dos materiais convencionais por nanomateriais que sejam ambientalmente amigáveis.

Sob essa perspectiva, a produção de Quantum Dots de Carbono (C-Dots) a partir resíduos industriais possibilita transformar matéria-prima barata e de baixo valor agregado em materiais de alta tecnologia. C-Dots são partículas de carbono com diâmetros inferiores a 10 $\mathrm{nm}$, com baixa toxicidade, e características espectroscópicas impressionantes que, desde que surgiram, recentemente, vêm tendo novas aplicações relatadas na literatura de maneira incessante, e que têm enorme potencial para aplicação em diversas áreas. Por outro lado, o bagaço de malte é o resíduo mais importante em termos de volume da indústria cervejeira. Esses resíduos são assumidamente uma rica fonte de carbono, podendo ser utilizados para a síntese de C-Dots. Atualmente, boa parte deste bagaço é destinada à alimentação animal, entretanto, a alta humidade desse material dificulta esta aplicação devido às dificuldades de transporte e armazenamento geradas pela alta proliferação microbiana. Sendo assim, a destinação desse subproduto continua sendo um problema para a sustentabilidade do processo de produção de cerveja, uma vez que o descarte inadequado do bagaço de malte pode ocasionar consequências ambientais sérias.

Este trabalho traz a produção de C-Dots a partir de bagaço de malte originado na produção de cerveja e a caracterização desse material. Duas rotas sintéticas foram escolhidas com o objetivo de obter-se nanomateriais com diferentes graus de oxidação superficial. Os CDots produzidos possuem a propriedade de upconversion (UC), que foi convenientemente 
estudada e explorada. Os C-Dots produzidos foram testados como sondas ópticas de imageamento celular (em células MCF-7).

\subsection{Objetivos gerais}

A proposta deste trabalho é a síntese de C-Dots a partir de bagaço de malte. Almeja-se, também, avaliar o efeito da etapa de oxidação da rota sintética nos nanomateriais. Considerando que os C-Dots possuem propriedades espectroscópicas incontestavelmente interessantes, úteis e ainda incompreendidas, buscamos explorar essas propriedades.

\subsection{Objetivos específicos}

- Obter C-Dots a partir de uma fonte de carbono não convencional: bagaço de malte;

- Sintetizar C-Dots através de diferentes rotas sintéticas e chegar ao melhor procedimento;

- Avaliar o efeito da etapa de oxidação nos nanomateriais resultantes;

- Explorar as propriedades espectroscópicas desses C-Dots;

- Investigar a aplicabilidade dos C-Dots em experimentos de imageamento celular. 


\section{Revisão Bibliográfica}

\subsection{C-Dots}

Desde que Smalley, Kroto, Curl e colaboradores reportaram a existência do fulereno, em $1985,{ }^{1}$ surgiu um interesse crescente na existência e propriedades de novas formas alotrópicas do carbono, além do diamante e do grafite, até então conhecidas. Em 1991, Iijima anunciou a descoberta do que ele chamou de estrutura de carbono finita constituída por tubos em forma de agulha, ${ }^{2}$ que hoje conhecemos como nanotubos de carbono. Em 2004, Geim, Novoselov e colaboradores divulgaram a síntese do grafeno, um material bidimensional a partir do qual é possível produzir-se filmes com camadas de até um átomo de espessura. ${ }^{3}$ Foi em 2004, também, que se iniciou a pesquisa envolvendo os C-Dots, também chamados de Dots de Carbono, Nanodots de Carbono, Quantum Dots de Carbono ou Quantum Dots de grafeno, ${ }^{4}$ quando Scrivens e colaboradores averiguaram que $10 \%$ da massa obtida em sua síntese de nanotubos de carbono eram devido à presença de uma mistura de nanopartículas luminescentes, compostas apenas por carbono, hidrogênio, oxigênio e nitrogênio. ${ }^{5}$ A figura 1 contém as estruturas das novas formas alotrópicas do carbono descobertas ao longo do tempo.

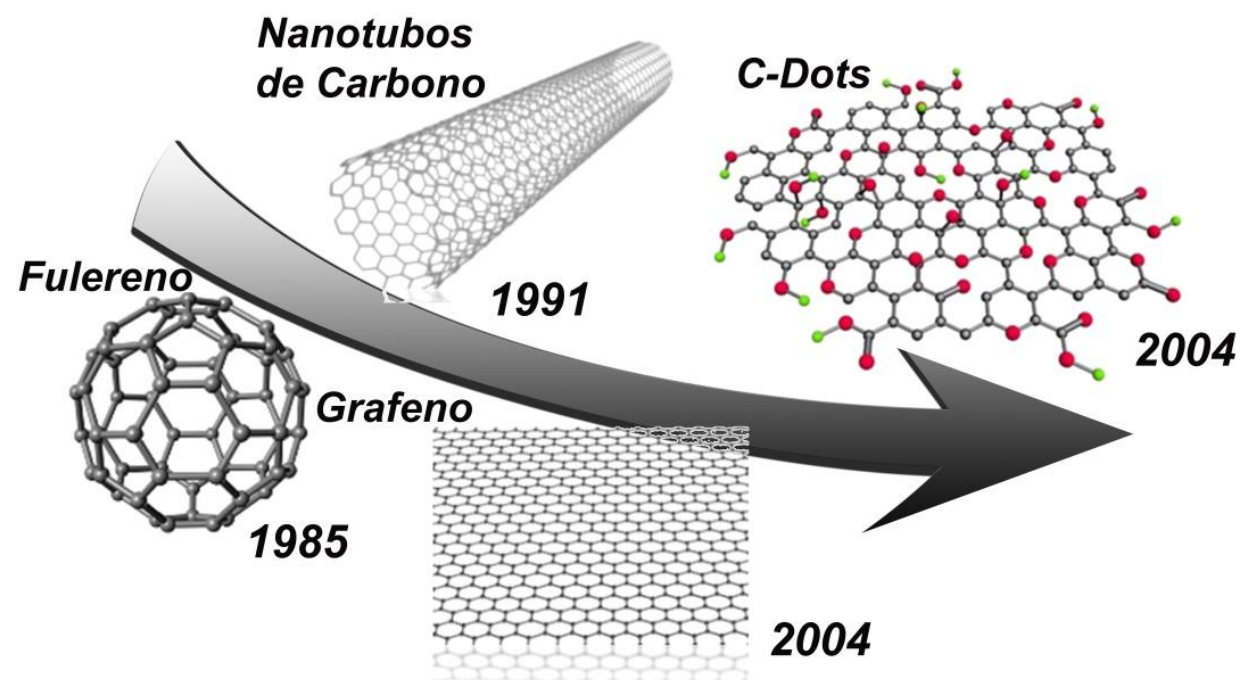

Figura 1- Descobertas das novas formas alotrópicas do carbono ao longo do tempo. As imagens das estruturas foram retiradas da referência 4. 


\subsubsection{Fontes de Carbono e Métodos de Síntese}

C-Dots são nanopartículas constituídas de carbono com hibridizações $\mathrm{sp}^{2}$ e $\mathrm{sp}^{3}$, heteroátomos e defeitos (causados pela presença de heteroátomos) ${ }^{4}$ com tamanhos abaixo de $10 \mathrm{~nm} .^{5}$ Essas nanopartículas possuem natureza grafítica, o que pode ser comprovado pela visualização de reticulados altamente cristalinos através de microscopia eletrônica de transmissão de alta resolução (MET). ${ }^{6}$ Eles podem ser obtidos a partir das mais diversas fontes de carbono, como glicose ${ }^{7}$ glicerol, ${ }^{8}$ compostos orgânicos aromáticos, ${ }^{9}$ sais de citrato, ${ }^{10}$ além de materiais como o próprio grafite, ${ }^{11}$ fulereno, ${ }^{12}$ nanotubos de carbono, ${ }^{13} \mathrm{e}$ fibras de carbono. ${ }^{14}$ Interessantemente os C-Dots também podem ser sintetizados a partir de fontes não convencionais, fontes essas que dispensam etapas de purificação preliminares, como cascas de melancia, ${ }^{15}$ cabelo, ${ }^{16}$ estrume de ruminantes, ${ }^{17}$ sucos de laranja ${ }^{18}$ ou banana, ${ }^{19}$ restos de comida, ${ }^{20}$ mel, ${ }^{21}$ e seda, ${ }^{22}$ por exemplo. A possibilidade de obtenção dos C-Dots através de fontes de carbono com baixo valor agregado os torna altamente atrativos, devido à diminuição de seu custo de produção.

Os métodos de síntese de C-Dots são igualmente variados e são divididos em métodos químicos e físicos. A importância de conhecer-se as variedades de fontes de carbono e meios sintéticos é que esses são fatores determinantes para a proporção entre os elementos químicos constituintes dos C-Dots, para o tamanho da nanopartícula e para o grau de oxidação de suas superfícies, e consequentemente têm influência direta em suas propriedades espectroscópicas. ${ }^{23}$ Alguns dos exemplos de métodos físicos são passivação por laser ${ }^{24} \mathrm{e}$ tratamento de plasma. ${ }^{25}$ Entre os exemplos de métodos sintéticos químicos estão a síntese eletroquímica, ${ }^{26}$ a oxidação química, ${ }^{27}$ a síntese de C-Dots utilizando-se suporte, ${ }^{28}$ a síntese por micro-ondas ${ }^{29}$ e a hidrotermal. ${ }^{30} \mathrm{~A}$ maioria dessas estratégias de síntese requerem reagentes de passivação superficial, e sem eles os C-Dots resultantes possuem baixos rendimentos quânticos. ${ }^{29}$ Das estratégias de obtenção de C-Dots aqui relatadas, o método de oxidação química destaca-se por exigir aparelhagem e reagentes quase sempre disponíveis em laboratórios químicos. ${ }^{31-32}$ A figura 2 ilustra a variedade de fontes e métodos sintéticos a partir dos quais C-Dots com natureza grafítica podem ser obtidos. 


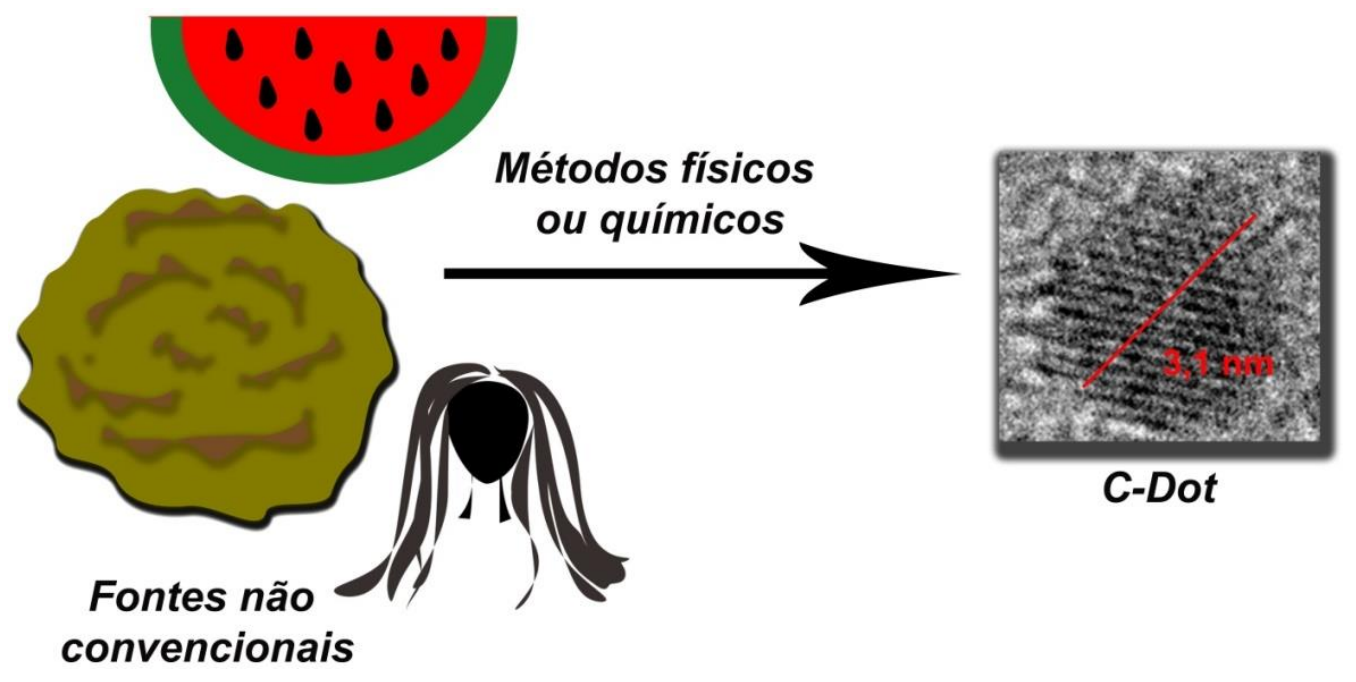

Figura 2- Fontes não convencionais (casca de melancia, estrume de ruminantes e cabelo) resultando em partículas de natureza grafítica como aquela cuja imagem de MET encontra-se nesta figura, com tamanhos abaixo de $10 \mathrm{~nm}$, e através de métodos físicos ou químicos.

\subsubsection{Propriedades Espectroscópicas}

O crescente interesse nos C-Dots se dá devido às propriedades espectroscópicas intrínsecas a eles. Essas nanopartículas são altamente fotoestáveis, o que permite aplicações com longos prazos de observação, ao contrário de corantes orgânicos, por exemplo. ${ }^{33}$ Uma característica notável do comportamento dos C-Dots é que sua emissão é dependente da excitação, e o comprimento de onda do pico de emissão pode ser ajustado em toda a janela visível, de 400 a $750 \mathrm{~nm}$, com o aumento progressivo do comprimento de onda de excitação ou com a separação das nanopartículas de acordo com seus tamanhos, como ilustrado na figura $3 .^{27}$ Além da fluorescência downconversion (DC), os C-Dots também apresentam fluorescências de dois fótons e de multifótons. ${ }^{4} \mathrm{O}$ resultado disso é a notável capacidade dos C-Dots, quando excitados por radiações da região do infravermelho próximo (NIR), de emitirem luz em comprimentos de onda menores do que os do NIR, que pode ser chamada de upconversion (UC). ${ }^{23} \mathrm{~A}$ importância disso é que, quando se trata de meios biológicos, é essencial que as radiações utilizadas não sejam detentoras de altas energias, porque estas são nocivas aos tecidos biológicos. ${ }^{34}$ 

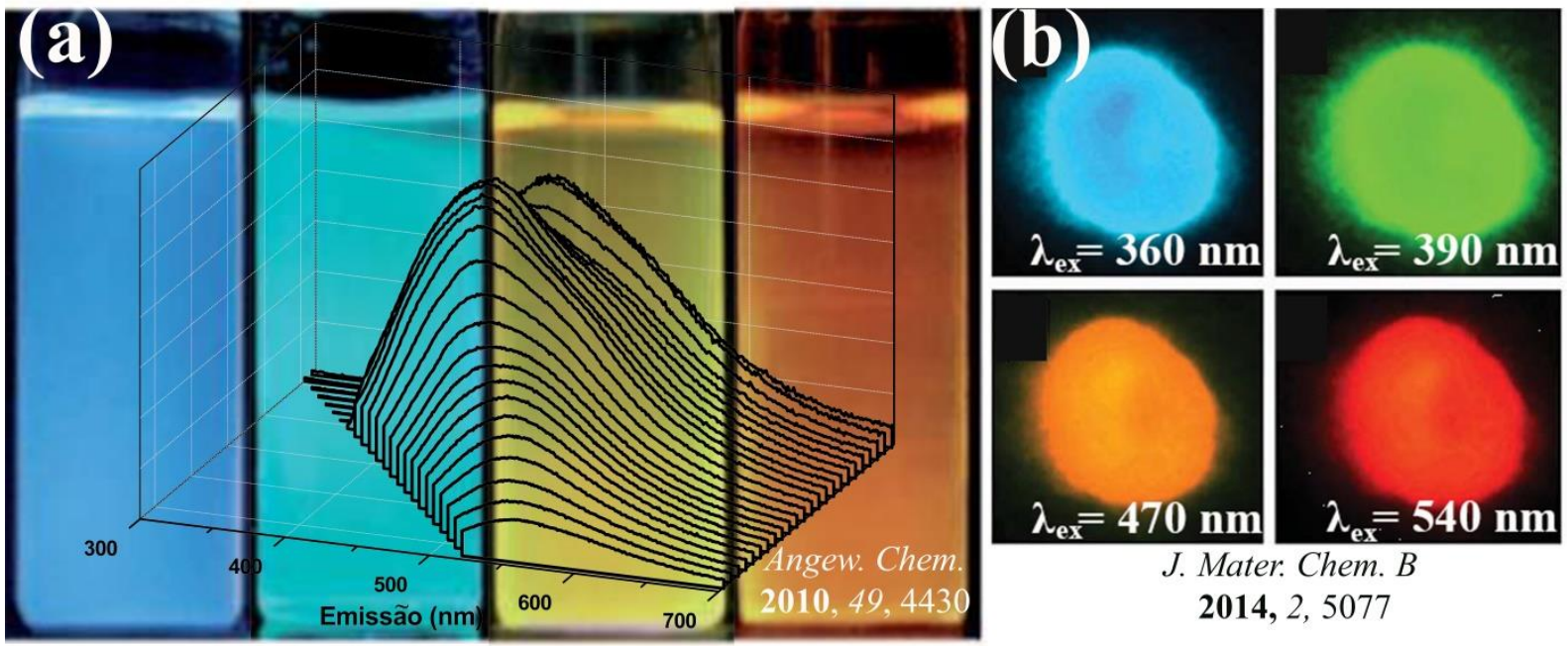

Figura 3- (a) espectros de emissão de C-Dots com máximos de intensidade dependentes do comprimento de onda de excitação. Imagens de C-Dots de diferentes tamanhos sob excitação de $365 \mathrm{~nm}$ no fundo. (b) C-Dots sob diferentes comprimentos de onda de excitação.

\subsubsection{Mecanismos de Emissão DC}

As origens das propriedades espectroscópicas dos C-Dots são assunto de muitas controvérsias e vários mecanismos têm sido especulados para serem os responsáveis pela luminescência desses materiais. Em algumas publicações, os autores atribuem as propriedades fotofísicas de seus C-Dots ao confinamento quântico resultado dos tamanhos nanoméricos das partículas, exclusivamente. ${ }^{35}$ Outra teoria é que as superfícies dos nanomateriais, produzidos por certas rotas sintéticas, apresentam armadilhas de energia que se tornam emissivas após a passivação superficial e que podem causar um efeito de confinamento quântico. ${ }^{27}$ Isso explicaria porque a passivação é tão importante para o rendimento quântico em alguns casos e, também, porque quanto maior a área superficial, maior a luminescência apresentada pela partícula. ${ }^{27}$

Existem ainda autores que acreditam em combinações de mecanismos. Baker e colaboradores ${ }^{6}$ postularam que C-dots apresentam gaps de energia dependentes de seus tamanhos, sendo as bandas de emissão mais intensas atribuídas à recombinação direta de pares elétron-buraco, enquanto as bandas menos intensas são devido à recombinação de armadilhas de energia superficiais assistida por fônon. A figura 4 ilustra este postulado e exemplifica os processos de passivação superficial. 
(a)

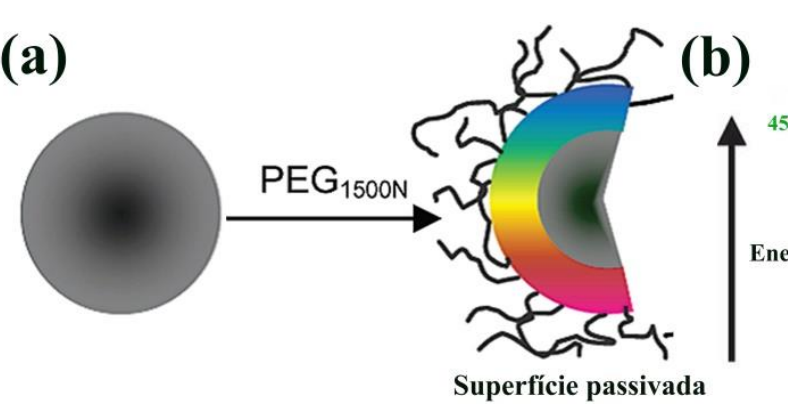

Superfície passivada (b)

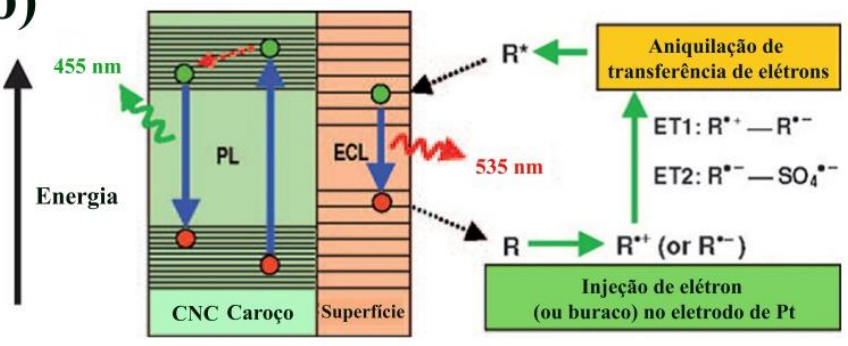

Figura 4- (a) passivação da superfície dos C-Dots (referência 27) (b) mecanismos de emissão dos C-Dots (referência 6).

Por outro lado, alguns autores sugerem a divisão dos mecanismos de emissão entre os de estado intrínseco (efeitos do confinamento quântico e sítios zig-zag) e de defeitos de estado (armadilhas de energia superficiais e efeito dos defeitos). ${ }^{34}$ Sob esta perspectiva, o fenômeno de recombinação de pares elétron-buraco localizados seria capaz de induzir os mecanismos de estado intrínseco. ${ }^{36}$ Esses dois grupos de mecanismos seriam os responsáveis pela emissão dos C-Dots, de forma que um se sobressairia em relação ao outro dependendo das características dos nanomateriais, como grau de oxidação superficial e tamanho médio, por exemplo. ${ }^{34}$ A figura 5 ilustra esses mecanismos.

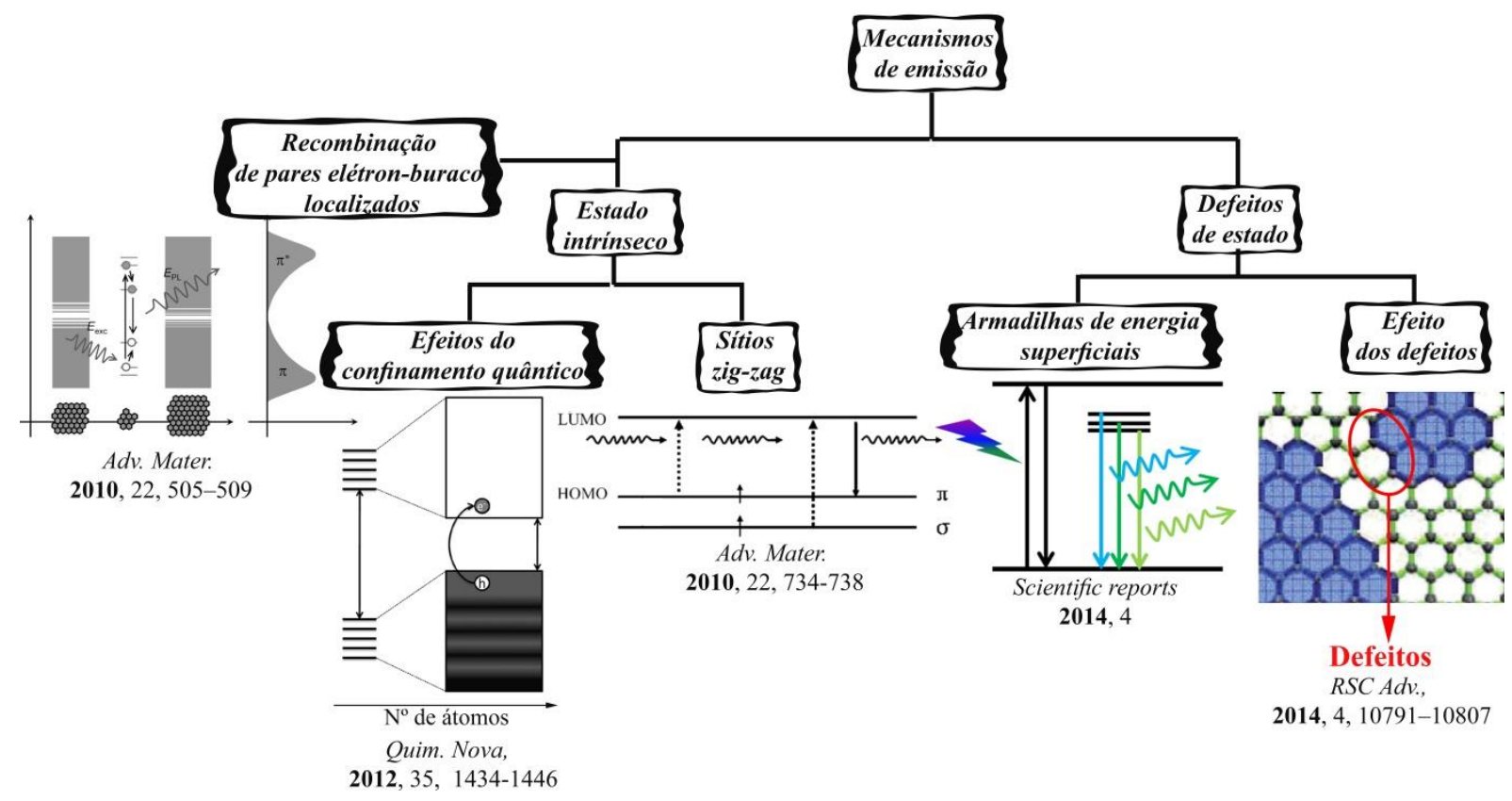

Figura 5- Alguns dos mecanismos responsáveis pelas emissões dos C-Dots, de acordo com classificação adotada por alguns autores. 


\subsubsection{Mecanismos de Emissão UC}

A procedência das propriedades de UC dos C-Dots também são alvo de debates intensos no meio acadêmico. Em diversas publicações reportando o comportamento de UC das nanopartículas, afirma-se que estas são resultadas de um processo ativo multifótons. ${ }^{35,37,38}$ Em contrapartida, Shen e colaboradores ${ }^{39}$ especulam que as emissões UC de seus C-Dots podem ser consideradas do tipo anti-Stokes. Dessa forma, o elétron partiria do orbital $\pi$ para o orbital desocupado de menor energia, após uma excitação de baixa frequência. Em seguida, ocorreria o decaimento radiativo, não para o orbital $\pi$, mas para $o \sigma$, que possui energia menor.

Além disso, três mecanismos principais foram propostos para esses materiais. São eles: processos de estados superficiais termicamente assistidos, absorção de dois fótons e recombinação Auger. ${ }^{40}$ Um método consolidado para o estudo de processos de UC é a avaliação da relação entre a intensidade da emissão $\left(\mathrm{I}_{\mathrm{em}}\right)$ e a intensidade de excitação $\left(\mathrm{I}_{\mathrm{ex}}\right)$ do material. Sabe-se que $\mathrm{I}_{\mathrm{em}}$ é proporcional a $\left(\mathrm{I}_{\mathrm{ex}}\right)^{\mathrm{n}}$, onde $\mathrm{n}$ é o número de fótons envolvidos no processo dominante de UC. ${ }^{41}$ Sob esta óptica, os mecanismos: processos de estados superficiais termicamente assistidos, absorção de dois fótons e recombinação Auger teriam os valores de $n$ iguais a 1,2 e 3 , respectivamente. ${ }^{40}$

Entretanto, em 2014, Wen e colaboradores ${ }^{41}$ chegaram à conclusão de que as propriedades de UC dos C-Dots reportadas na literatura até então, que eram constatadas através de medidas com espectrofluorímetros típicos, eram apenas a emissão DC dos materiais provocadas pelas radiações de segunda ordem de difração, produzidas no monocromador, que também passam pela fenda de excitação dos fluorímetros quando as medidas são realizadas sem filtros adequados. $\mathrm{O}$ valor de $\mathrm{n}$ encontrado nos experimentos de Wen e colaboradores ${ }^{41}$ é de aproximadamente 1 , e a possibilidade de os fenômenos de UC serem provocados por processos de estados superficiais termicamente assistidos não é considerada por esse grupo.

Desde então, trabalhos foram publicados, não exclusivamente baseados em medidas tomadas em espectrofluorímetros, comprovando a existência de UC nos C-Dots. Um bom exemplo é o estudo de autoria de Zhang e colaboradores ${ }^{42}$ que comprova a presença do fenômeno de UC em seus C-Dots em cujo mecanismo está envolvida a absorção de 2 fótons $(n=2)$. A figura 6 ilustra os mecanismos de UC propostos pelos grupos de Shen e Zhang. 


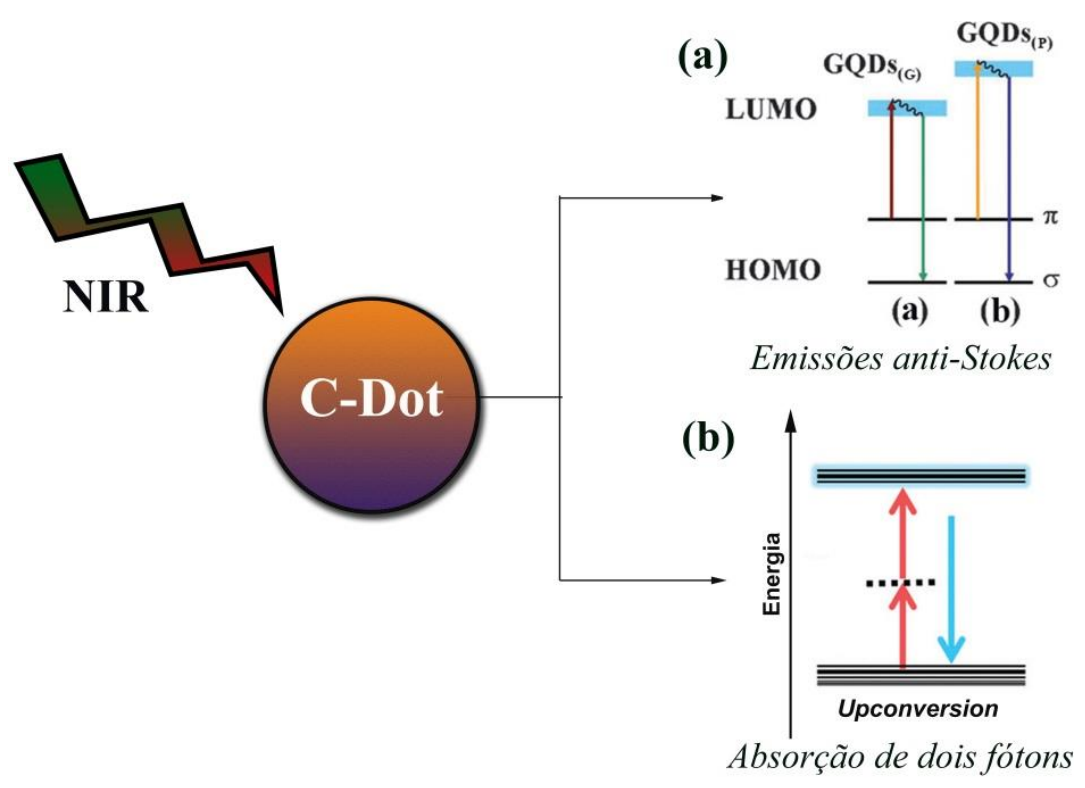

Figura 6- Mecanismos de UC: (a) emissões anti-Stokes (referência 39); (b) por absorção de dois fótons (referência 42).

\subsubsection{Aplicações}

As características dos C-Dots relatadas até aqui conferem a eles potencial para o desenvolvimento das mais diversas tecnologias. ${ }^{4}$ Ademais, os C-Dots mostram-se capazes de atuarem tanto como aceptores quanto como doadores de elétrons, ao terem suas emissões extintas em soluções contendo moléculas com excesso ou deficiência de elétrons. ${ }^{23}$ Isso os torna interessantes para fins como a utilização em dispositivos fotovoltaicos, ${ }^{43}$ para aplicações relacionadas à conversão de energia luminosa, e até mesmo para investigação de mecanismos. ${ }^{44}$ A utilização das nanopartículas como nanosondas para a detecção de íons, também, já foi reportada. ${ }^{45-46}$

Além disso, os C-Dots têm sido largamente utilizados para uma grande variedade de aplicações biomédicas, incluindo imageamento por DC de células em vitro e em vivo, ${ }^{47}$ terapia fotodinâmica ${ }^{48} \mathrm{e}$ imageamento por fluorescência multifóton de células e tecidos. ${ }^{24}$ Pesquisas recentes revelaram que a similaridade de tamanho entre os C-Dots $(\sim 5 \mathrm{~nm})$ e as proteínas fluorescentes (FPS, $\sim 4 \mathrm{~nm}$ ), permite que os C-Dots sejam utilizados como sondas fluorescentes. $^{49}$ Os C-Dots também possuem grande potencial para o carreamento de fármacos, ${ }^{50}$ como Dai e colaboradores demonstraram ao fazer o carreamento de drogas insolúveis utilizadas no tratamento contra o câncer através de um compósito com os 
nanomateriais. ${ }^{51}$ A eficiência dos C-Dots para as aplicações em meio biológico se dá devido a sua não toxicidade e inércia química em condições fisiológicas. ${ }^{52}$ A presença de grupos superficiais contendo oxigênio também colabora para a alargar o rol de aplicabilidade das nanopartículas, já que possibilita a interação dos C-Dots com moléculas orgânicas e inorgânicas. ${ }^{53}$ A figura 7 apresenta algumas das aplicações supracitadas dos C-Dots.

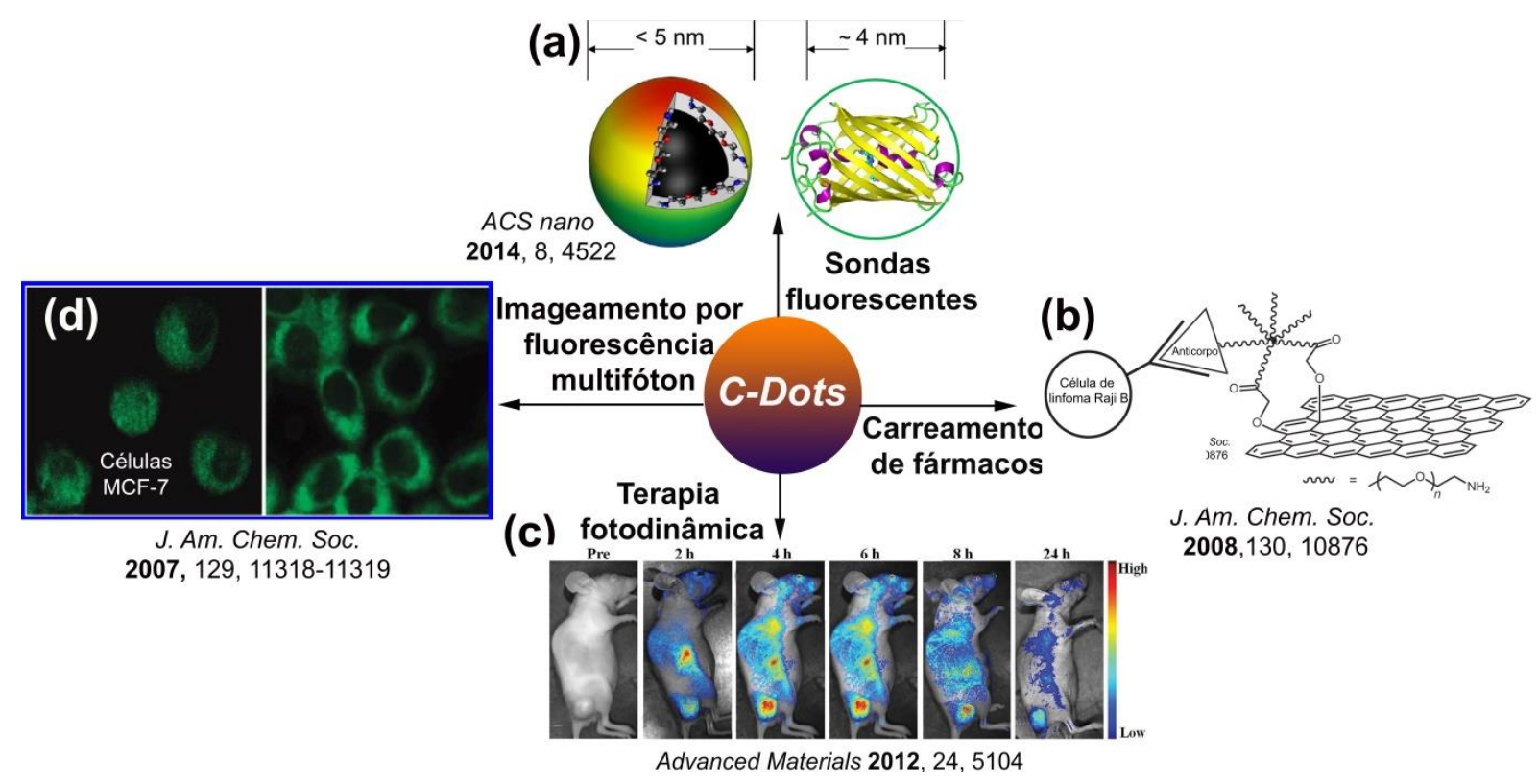

Figura 7- Ilustrações e experimentos de algumas das aplicações em meio biológico dos C-

Dots: (a) sondas fluorescentes, referência 49; (b) carreamento de fármacos usados no tratamento contra o câncer, referência 51; (c) imagens de fluorescência in vivo NIR em tempo real após a injeção intravenosa de C-Dots em ratinhos nus, em diferentes pontos temporais, referência 48; (d) imagem de luminescência de dois fótons $\left(\lambda_{\mathrm{ex}}=800 \mathrm{~nm}\right)$ de células humanas de câncer de mama MCF-7, referência 24.

Os C-Dots são alternativas altamente promissoras a materiais cujas aplicações biológicas já estão difundidas no maio acadêmico. Quando comparados aos nanotubos de carbono, por exemplo, os C-Dots apresentam alta solubilidade em água, sem tratamentos adicionais, ausência de metais contaminantes, devido a não necessidade de catalizadores em seu processo de síntese, maior área superficial e ainda dispensam o uso de surfactantes para a dispersão, que podem ser fonte de toxicidade. ${ }^{53}$ Já quando comparados aos quantum dots semicondutores tradicionais, os C-Dots se sobressaem ainda mais. Os quantum dots semicondutores apresentam elementos tóxicos, como cádmio, chumbo e mercúrio em sua composição, o que é um grande obstáculo às suas aplicações em vivo. ${ }^{54}$ 


\subsection{Bagaço de Malte}

A cerveja é a terceira bebida mais consumida no mundo. ${ }^{55}$ No Brasil, seu consumo per capita anual era cerca de 57 L em 2008, sendo o nosso país o terceiro maior produtor mundial de cerveja, com uma produção anual de 12,6 milhões de litros. ${ }^{56}$

O processo de produção de cerveja gera três resíduos principais: o bagaço de malte, o trub quente (precipitado advindo da coagulação e insolubilização de proteínas no mosto, durante a etapa de fervura) e a levedura cervejeira residual. ${ }^{57}$ A figura 8 ilustra a geração desses refugos no processo de produção de cerveja. Desses materiais, o bagaço de malte é o que gera o maior volume, são de 14 a $20 \mathrm{~kg}$ para cada $100 \mathrm{~L}$ de cerveja produzida, ${ }^{58}$ representando cerca de $85 \%$ do montante de resíduos gerados pela indústria cervejeira. Esse subproduto é formado pela parte sólida obtida na etapa de filtração do mosto, antes da fervura. $^{57}$

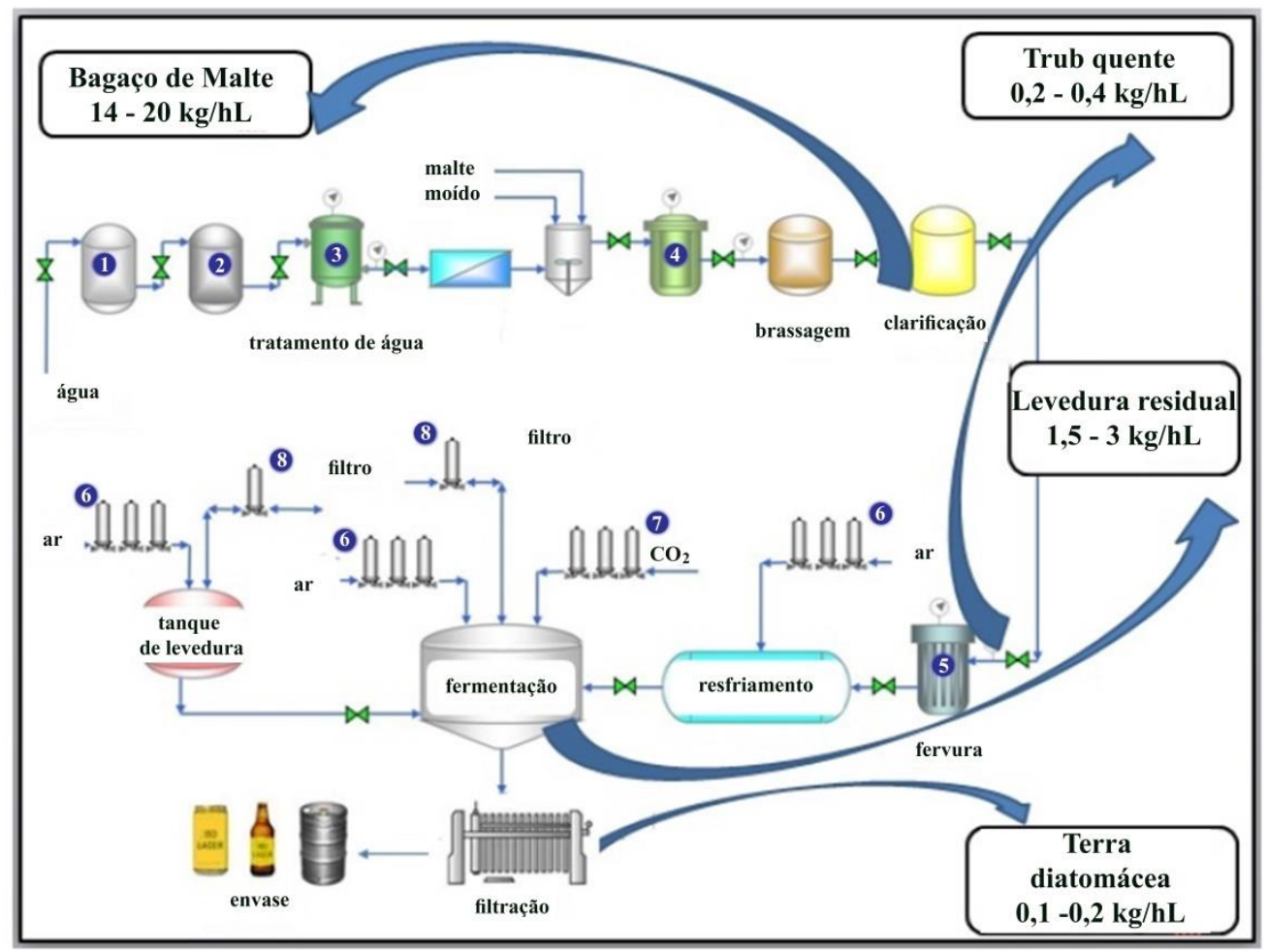

Figura 8- Fluxograma de uma indústria cervejeira e a geração de resíduos. Figura adaptada da referência 57.

O bagaço de malte é constituído de material fibroso - celulose (15,5 a 25\%), hemiceluloses (28 a 30\%) e lignina (28\%) -, de proteínas (15 a 26.2\%) e de lipídios, vitaminas, aminoácidos e compostos fenólicos. ${ }^{57} \mathrm{~A}$ proporção entre estes constituintes 
depende da espécie da cevada, dos processos de malteamento, moagem e clareamento, e também da presença ou não de adjuntos, como outros cereais ou fontes de açúcares. ${ }^{59}$

A destinação do bagaço de malte é de extrema importância para a sustentabilidade do processo de produção de cerveja. Isto porque a alta umidade desse material favorece a proliferação microbiana e pode causar desequilíbrios ambientais em caso de descarte inadequado. Ademais, o alto teor de matéria orgânica no bagaço tem como consequência uma alta Demanda Bioquímica de Oxigênio, o que dificulta sua decomposição. ${ }^{57}$

O principal destino dado ao bagaço de malte é a alimentação de animais, especialmente na bovinocultura. Entretanto, a prática de alimentar os ruminantes com esse resíduo sólido sem o manejo e o armazenamento pertinentes pode causar doenças no rebanho como intoxicação por Aspergillus clavatus, acidose ruminal e botulismo. ${ }^{60}$ Além disso a utilização do bagaço nas produções de energia e carvão vegetal, ${ }^{59}$ e de espumas biodegradáveis ${ }^{61}$ já foram reportadas na literatura. O baixo ou nulo custo do bagaço de malte ${ }^{59}$ é uma grande vantagem de sua utilização como matéria-prima para a produção de tecnologias. 


\section{Materiais e métodos}

\subsection{Reagentes}

Os reagentes ácido nítrico e hidróxido de sódio foram adquiridos da empresa Sigma-Aldrich e utilizados sem purificação prévia. O bagaço de malte foi obtido após produção de cerveja executada para o trabalho final da disciplina Fundamentos de Produção de Cerveja, ministrada pela professora Grace Ferreira Ghesti.

\subsection{Síntese dos C-Dots}

Duas rotas experimentais foram utilizadas com o objetivo de produzir C-Dots com diferentes graus de oxidação. Esses nanomateriais foram designados como 1 e 2, referindo-se ao mais oxidado e ao menos oxidado, respectivamente. Os procedimentos experimentais estão resumidos no esquema 1.

Os C-Dots 1 foram sintetizados pelo método de oxidação química. ${ }^{17} 5 \mathrm{~g}$ de bagaço de malte foram lavados com água destilada em um erlenmeyer (de forma que restassem apenas as cascas de grãos) e calcinados à $300{ }^{\circ} \mathrm{C}$ por $3 \mathrm{~h}$, em mufla. $\mathrm{O}$ pó resultante foi submetido a refluxo com solução aquosa de ácido nítrico $(5 \mathrm{M}, 100 \mathrm{~mL})$, por 24 h. Quando a suspensão foi resfriada, à temperatura ambiente, o $\mathrm{pH}$ foi elevado para 5-7 com $\mathrm{NaOH}$. Em seguida, a solução foi filtrada com papel filtro, para remover as partículas maiores, e sonicada por 90 min. A solução resultante foi filtrada através de uma membrana de 0,22 $\mu \mathrm{m}$. A água foi então evaporada em um béquer aberto, dando origem a $\mathbf{1}$.

De forma similar, os C-Dots 2 foram preparados a partir de $5 \mathrm{~g}$ de bagaço de malte, que foram lavados com água destilada e calcinados à $300{ }^{\circ} \mathrm{C}$ por $3 \mathrm{~h}$. O pó obtido foi dissolvido em água destilada, e a solução teve seu pH controlado para 5-7 com NaOH. Em seguida, uma filtração com papel filtro foi realizada e a solução foi sonicada por 90 min. O próximo passo foi a filtração por uma membrana de $0,22 \mu \mathrm{m}$. A água foi então evaporada em um béquer aberto, originando os C-Dots 2. 


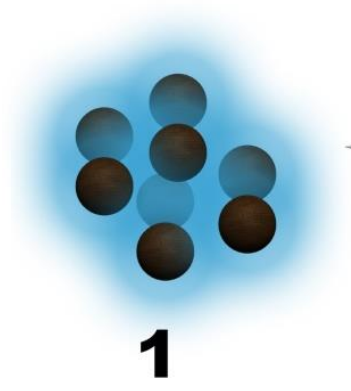

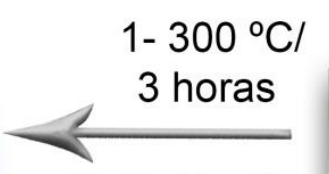

2- Oxidação

3- Extração Bagaço de malte $1-300^{\circ} \mathrm{Cl}$

3 horas

2- Extração

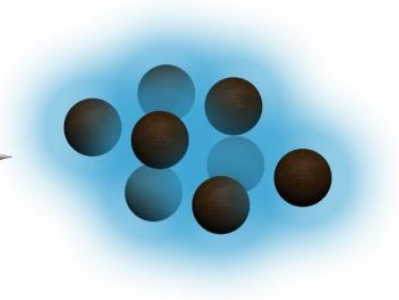

2

Esquema 1- Resumo dos procedimentos sintéticos utilizados para a obtenção dos C-Dots $\mathbf{1}$ e 2.

\subsection{Experimentos de Imageamento Celular}

Os experimentos de imageamento celular foram realizados em cooperação com o grupo do Prof. Dr. José Raimundo Correa, do Departamento de Biologia Celular, do Instituto de Biologia, Universidade de Brasília, com especial colaboração de Lorena Pereira de Andrade.

Os ensaios em células vivas foram realizados da seguinte maneira: células MCF-7 (de câncer de mama) foram plaqueadas em lamelas de vidro redondas de $13 \mathrm{~mm}$, na parte inferior de uma placa de 24 poços e deixadas para aderir a $37{ }^{\circ} \mathrm{C}$, numa atmosfera de $5 \%$ de $\mathrm{CO}_{2}$, durante 30 min. Então, a placa foi lavada com meio isento de soro, a fim de remover as células não aderidas. As células MCF-7 foram cultivadas em meio de Eagle modificado por Dulbecco (DMEM) suplementado com $10 \%$ de Soro Fetal Bovino (SFB), a $37{ }^{\circ} \mathrm{C}$, em atmosfera de $5 \%$ de $\mathrm{CO}_{2}$.

Para os experimentos com células fixadas, o procedimento descrito acima foi realizado, acrescido das seguintes etapas: quando a confluência foi atingida (momento em que as células recobrem toda a superfície da placa, formando uma monocamada), a cultura foi lavada três vezes com solução tampão fosfato salino (PBS), pH 7,4, e fixada por 15 min em solução de formaldeído $(3,7 \%)$ em PBS à temperatura ambiente. As células foram lavadas três vezes com PBS.

As células vivas e fixadas foram, então, incubadas com os C-Dots 1 (soluções aquosas de 2,5 mg.mL ${ }^{-1}$ ) por $30 \mathrm{~min}$, à temperatura ambiente. Elas também foram incubadas em PBS, sob as mesmas condições, para a obtenção do controle negativo. Após o período de incubação, as células foram lavadas três vezes com PBS e incubadas com 4',6-diamidino-2- 
fenilindol (DAPI; Invitrogen, Oregon, EUA), de acordo com as recomendações do fabricante. ProLong Gold Antifade (Invitrogen, Oregon, USA) foi utilizado de acordo com as recomendações do fabricante para montar as lamelas. Todos os ensaios foram realizados em três séries independentes.

\subsection{Métodos de caracterização}

Os seguintes métodos e equipamentos foram utilizados para a caracterização dos materiais desenvolvidos neste trabalho:

- Espectroscopia de fluorescência- Os espectros de fluorescência foram adquiridos de soluções aquosas dos materiais $\left(2 \mathrm{mg} \cdot \mathrm{mL}^{-1}\right)$, em cubeta de quartzo com caminho óptico de $1 \mathrm{~cm}$, usando-se um espectrômetro Lumina Fluorescence (Thermo Scientific), com um sistema de peltier para variar a temperatura, quando necessário. Soluções aquosas de ácido clorídrico e hidróxido de sódio foram utilizadas nos experimentos de variação de $\mathrm{pH}$;

- Espectroscopia na região do infravermelho (IV)- Os espectros de IV foram registrados de pastilhas de $\mathrm{KBr}$, na região espectral de 4000-400 $\mathrm{cm}^{-1}$, utilizando-se um espectrômetro Jasco FT/IR-4100;

- Espectroscopia na região do ultravioleta-visível (UV-Vis)- Os espectros de UV-Vis foram registrados de soluções aquosas de $0,4 \mathrm{mg} \cdot \mathrm{mL}^{-1}$ dos nanomateriais, em cubeta de quartzo com caminho óptico de $1 \mathrm{~cm}$, usando-se um espectrofotômetro Agilent Technologies Cary 8454;

- Espectroscopia raman- Os espectros de raman foram adquiridos em cooperação com o grupo do Prof. Dr. Jorlandio Francisco Felix, do Núcleo de Física Aplicada, do Instituto de Física, Universidade de Brasília. O equipamento utilizado foi um Renishaw InVia micro-Raman System, equipado com um laser de argônio com linha em $514,5 \mathrm{~nm}$ e feixe de aproximadamente $1 \mu \mathrm{m}$. A potência do laser de excitação era de aproximadamente $0,05 \mathrm{~mW}$ na superfície das amostras, que foram medidas em estado sólido;

- Microscopia confocal a laser- As culturas de células foram analisadas em um microscópio confocal Leica TCS SP5 (Mannheim, Alemanha), em parceria com o grupo do Prof. Dr. José Raimundo Correa, do Departamento de Biologia Celular, do Instituto de Biologia, Universidade de Brasília; 
- Microscopia eletrônica de transição de alta resolução (MET)- as imagens de MET foram obtidas em um microscópio eletrônico JEOL JEM 2010, operando a uma voltagem de aceleração de $200 \mathrm{kV}$. As soluções aquosas dos materiais a serem analisados foram depositadas em uma tela de cobre revestida com carbono de 400 malhas (Ted Pella Inc- USA) e secas ao ar;

- Potencial zeta- Os potenciais zeta foram medidos em um Zetasizer Nano-ZS90, de soluções aquosas $\left(2 \mu \mathrm{g} . \mathrm{mL}^{-1}\right)$ em $\mathrm{pH} 5$ das amostras. As medidas foram realizadas em triplicata. 


\section{Resultados e discussão}

\subsection{Comparação entre C-Dots produzidos através de diferentes rotas sintéticas}

Bagaço de malte é, assumidamente, uma fonte abundante de carbono considerando-se que é gerado na etapa de filtração do mosto na fabricação de cerveja, dando origem a um resíduo que é constituído principalmente por proteínas insolúveis, celulose e lignina. ${ }^{61}$ Tendo em vista a geração anual de grandes quantidades desse subproduto (para cada $100 \mathrm{~L}$ de cerveja produzida, até $20 \mathrm{~kg}$ de bagaço de malte são gerados ${ }^{61}$ ), decidimos explorá-lo como fonte de carbono para sintetizar C-Dots, através de duas rotas sintéticas cujos materiais resultantes foram chamados de $\mathbf{1}$ e $\mathbf{2}$.

O grau de oxidação da superfície dos C-Dots é reconhecidamente influenciado pela rota sintética. ${ }^{62} \mathrm{O}$ processo de oxidação proporciona a formação de domínios $\mathrm{sp}^{3}$ na superfície do C-Dots, resultando na inserção de diferentes grupos funcionais na superfície, tais como grupos carboxílicos e hidroxílicos. ${ }^{63} \mathrm{~A}$ presença desses grupos funcionais oxigenados desempenha um papel importante sobre as propriedades hidrofílicas dos derivados de C-Dots e também permite o desenvolvimento de biosondas mais específicas através de modificações químicas simples. ${ }^{17} \mathrm{O}$ que se esperava das rotas sintéticas utilizadas para a produção dos CDots é que a etapa de oxidação com ácido nítrico da síntese de 1 tenha decorado suas superfícies com uma quantidade de grupos oxigenados maior do que o número de grupos existentes na superfície de 2, como ilustrado na figura 9. Os valores de potencial zeta, adquiridos em meio aquoso, $\mathrm{pH} 5$, foram de $-13,3 \mathrm{mV}$ e $-8,89 \mathrm{mV}$ para $\mathbf{1}$ e 2, respectivamente, que são comparáveis a valores relatados anteriormente. ${ }^{64-65} \mathrm{O}$ aumento do potencial zeta observado para $\mathbf{2}$ sustenta a hipótese de que a superfície de $\mathbf{1}$ é mais oxidada, com mais grupos $\mathrm{COO}^{-}{ }^{66}$ 

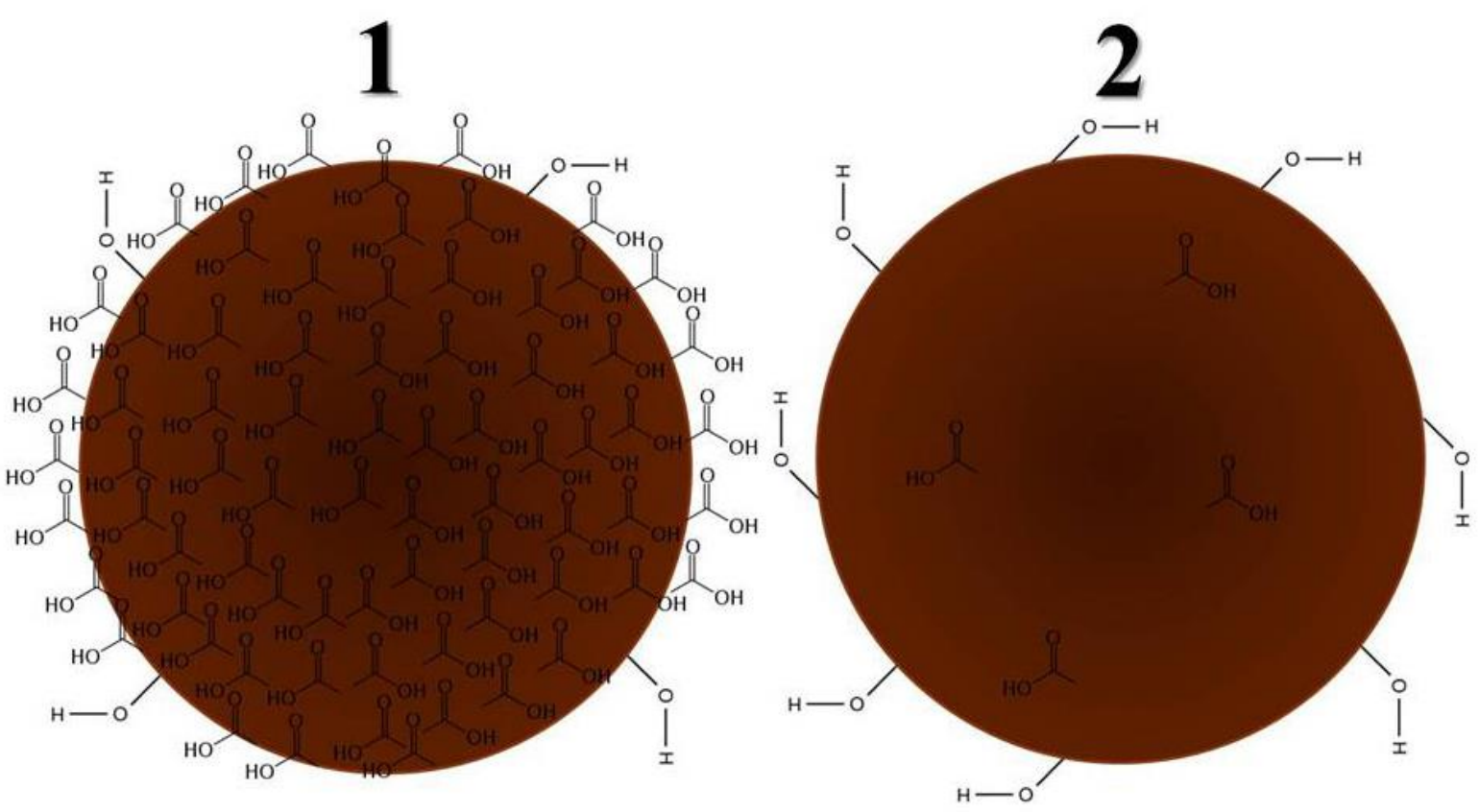

Figura 9- Ilustrações dos C-Dots 1 e 2.

As imagens de MET adquiridas de $\mathbf{1}$ e $\mathbf{2}$ (figura 10) mostram partículas bem dispersas com morfologias esféricas. 1 e $\mathbf{2}$ apresentam faixas de distribuição de tamanho estreitas, variando de 2.5 a $5.9 \mathrm{~nm}$ e de 2,5 a $5,3 \mathrm{~nm}$, com tamanhos médios de 4,08 e 3,72 nm, respectivamente. Nas figuras 10 (d) e 10 (e), são apresentadas imagens representativas de partículas individuais, indicando a elevada cristalinidade dos materiais, com parâmetros de rede de 3,13 e $3,15 \AA$, o que corresponde ao plano de difração do grafite [002]. ${ }^{67}$ Estes resultados mostram que ambas as vias sintéticas resultaram em nanopartículas uniformes com distribuições de tamanho semelhantes. 

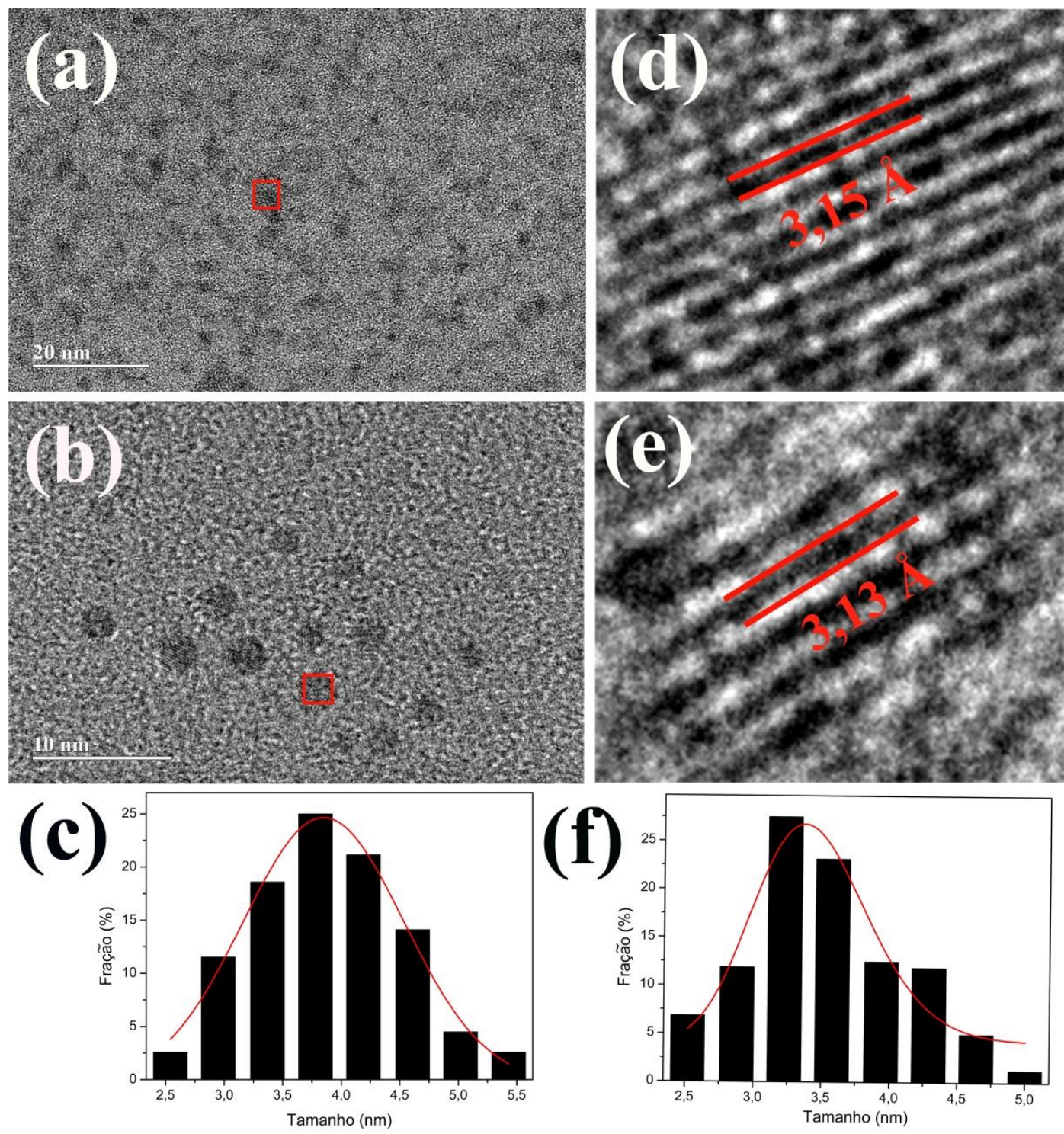

Figura 10- (a) e (b): imagens de MET dos C-Dots 1 e 2. (c) e (f): zoom das regiões marcadas das figuras (a) e (b), respectivamente, enfatizando os parâmetros de rede de partículas representativas. (d) e (e): histogramas de distribuição de tamanho de $\mathbf{1}$ e $\mathbf{2}$.

A técnica de absorção molecular na região do infravermelho é extremamente útil para a identificação de grupos funcionais em moléculas dotadas de momento dipolar diferente de zero, como é o caso dos C-Dots. A radiação infravermelha provoca uma mudança líquida no momento dipolar da molécula, causando seu movimento de vibração ou rotação. A frequência da radiação absorvida é quantizada e depende da massa dos átomos envolvidos na ligação e da força dessas ligações. ${ }^{68}$ Os espectros de IV (figura 11) dos C-Dots 1 e 2 apresentam bandas de absorção intensas centradas em $3450 \mathrm{~cm}^{-1}$, que são atribuídas ao estiramento das ligações OH. Já as bandas centradas em $1630 \mathrm{~cm}^{-1}$ foram atribuídas a vibrações assimétricas dos grupos 
$\mathrm{C}=\mathrm{O}$. Essas bandas confirmam a presença de grupos carboxílicos nas superfícies de $\mathbf{1}$ e $\mathbf{2}$. Além disso, ambos os espectros apresentam bandas centradas em 2870, 2760 e $1380 \mathrm{~cm}^{-1}$, atribuídas aos estiramentos assimétricos e simétricos da ligação $\mathrm{C}-\mathrm{H}$ e à deformação $\mathrm{C}-\mathrm{H}$, respectivamente. Esses picos sugerem que existem grupos metila ligados à superfície das nanopartículas. ${ }^{69}$

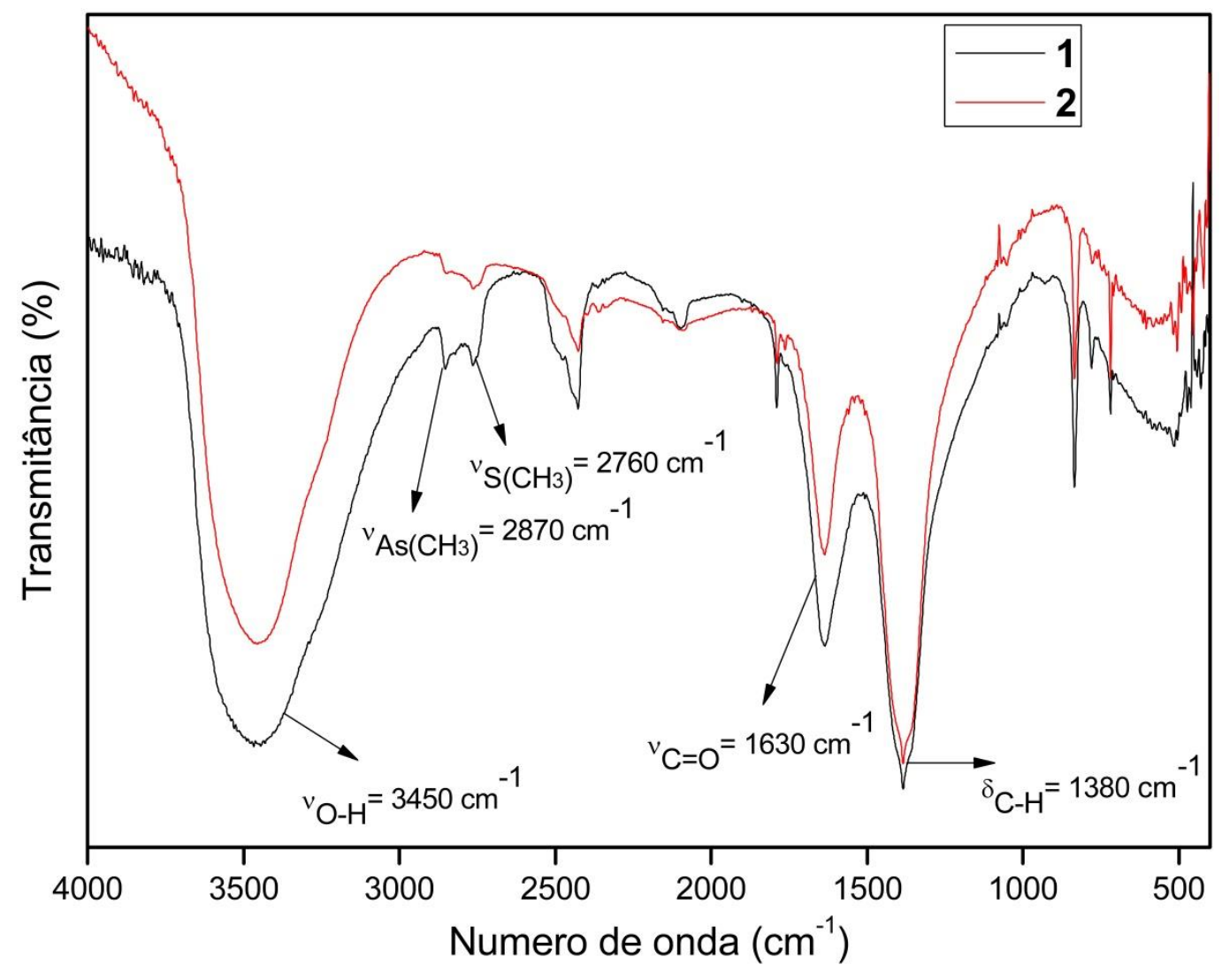

Figura 11- Espectros de IV dos materiais. As curvas em preto e vermelho referem-se às amostras 1 e 2 , respectivamente.

A espectroscopia Raman é um instrumento eficaz quando se trata do estudo da cristalinidade de materiais. ${ }^{70} \mathrm{O}$ espalhamento Raman dos C-Dots $\mathbf{1}$ em temperatura ambiente está disponível na figura 12. Os C-Dots 2 exibiram um perfil idêntico. Os picos por volta de 724 e $1068 \mathrm{~cm}^{-1}$ correspondem aos modos de vibração $\mathrm{A}_{1 \mathrm{~g}}$ e $\mathrm{E}_{\mathrm{g}}$ do nitrato de sódio cristalino, respectivamente. ${ }^{71}$ Os outros dois picos (1380 e $\left.1577 \mathrm{~cm}^{-1}\right)$ são geralmente observados para materiais à base de grafite. A banda $\mathrm{D}\left(1380 \mathrm{~cm}^{-1}\right)$ indica a presença de defeitos $\mathrm{sp}^{3}$, já o pico em torno de $1577 \mathrm{~cm}^{-1}$ (banda $\mathrm{G}$ ) é atribuído à presença de carbonos $\mathrm{sp}^{2}{ }^{72}$ A razão entre as intensidades relativas das bandas $\mathrm{D}$ e $\mathrm{G}\left(\mathrm{I}_{\mathrm{D}} / \mathrm{I}_{\mathrm{G}}\right)$ fornece o grau de desordem do material, e é uma ferramenta importante para a comparação entre as ordens estruturais de diferentes 
sistemas grafíticos. ${ }^{73-74} \mathrm{O}$ valor da razão $\left(\mathrm{I}_{\mathrm{D}} / \mathrm{I}_{\mathrm{G}}\right)$ para os C-Dots sintetizados neste trabalho foi de cerca de 0,95. A predominância de carbonos $\mathrm{sp}^{2}$ apresentada por nossos nanomateriais é uma característica marcante da formação de C-Dots. ${ }^{23}$ Os resultados dos experimentos de Raman mostraram-se de acordo com os relatados para C-Dots sintetizados a partir de outras fontes de carbono não convencionais. ${ }^{15,72,75}$

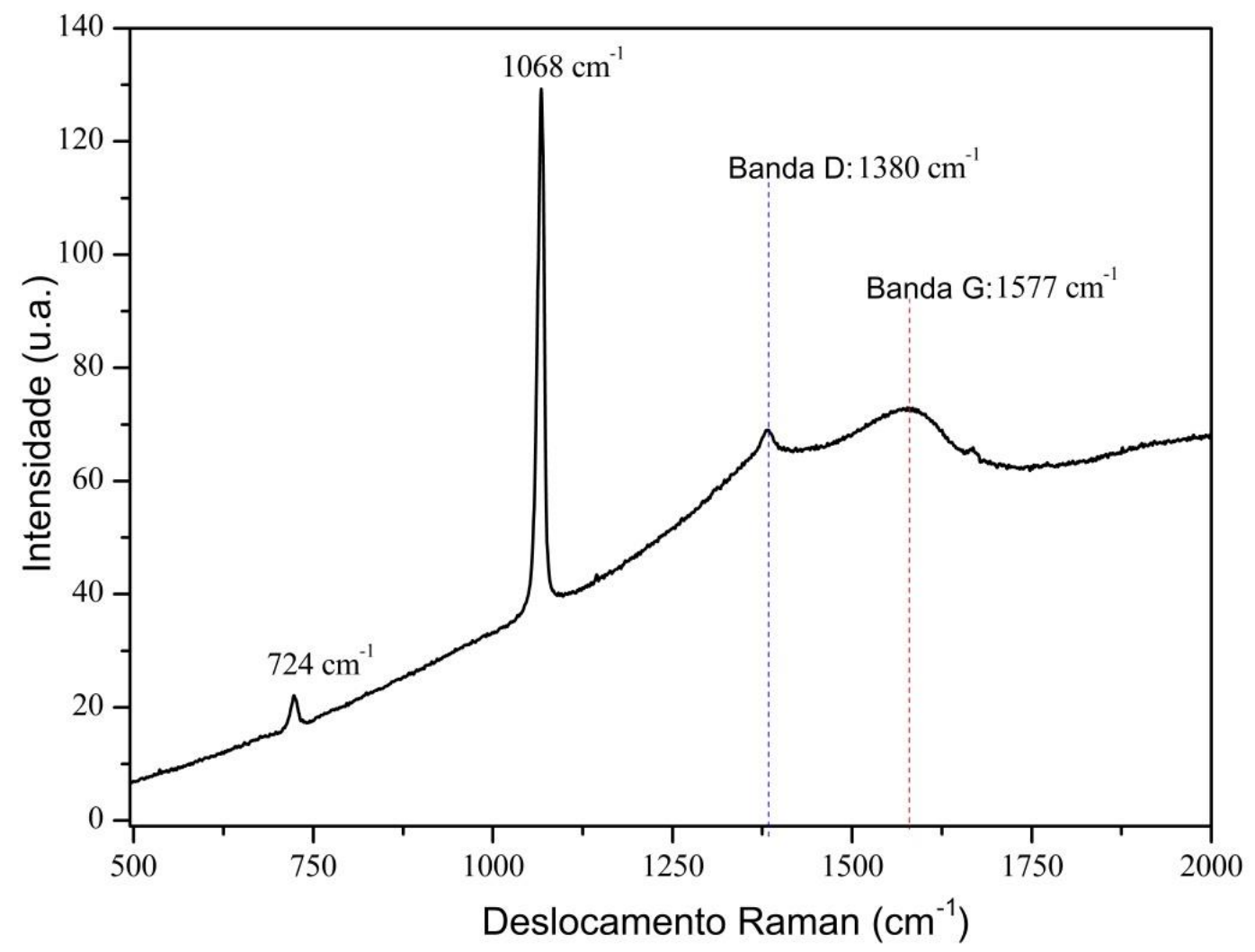

Figura 12- Espectro de Raman dos C-Dots 1. C-Dots 2 apresentaram perfil idêntico.

As propriedades ópticas dos C-Dots 1 e 2 foram estudadas por espectroscopia na região do UV-Vis e espectroscopia de fotoluminescência. Os espectros de absorção no UVVis, exibidos na Figura 13, mostram uma banda intensa em $228 \mathrm{~nm}$, que pode ser correlacionada com as transições $n-\pi^{*}$. Além disso, ombros de absorção de baixa intensidade foram observados por volta de $305 \mathrm{~nm}$, e foram atribuídos às transições $\pi-\pi^{*}$ dos grupos funcionais da superfície dos C-Dots. A diferença no grau de oxidação de C-Dots não altera o seus perfis de absorção, assim, as energias associadas com a formação dos éxcitons (pares ligados elétron-buraco) em $\mathbf{1}$ e $\mathbf{2}$ são muito semelhantes. Os espectros de emissão de $\mathbf{1}$ e $\mathbf{2}$, medidos a temperatura ambiente, sob excitação de 300 nm, também são mostrados na Figura 13 e exibem bandas largas centradas em 460 e $440 \mathrm{~nm}$, respectivamente. A origem das 
propriedades ópticas dos C-Dots ainda não é bem compreendida, como discutido anteriormente. Segundo Zhu e colaboradores,${ }^{34}$ os grupos carboxílicos superficiais facilitam a recombinação não-radiativa de pares localizados elétron-buraco, o que desfavorece os mecanismos de emissão de estado intrínseco. Por esse motivo, o maior grau de oxidação da nanopartícula se traduziria em um deslocamento batocrômico da emissão, como foi observado experimentalmente. Por outro lado, Bao e colaboradores ${ }^{62}$ especulam que os mecanismos de emissão de defeitos de estado desempenham papel mais importante para a emissão dos CDots do que os efeitos de tamanho da partícula (mecanismo de emissão de estado intrínseco). Dessa forma, um maior grau de oxidação aumentaria a quantidade de defeitos superficiais, que poderiam aprisionar mais éxcitons. Um deslocamento batocrômico da emissão, como o experimentado por $\mathbf{1}$ comparado a $\mathbf{2}$, seria, também, observado por causa da recombinação dos éxcitons aprisionados.

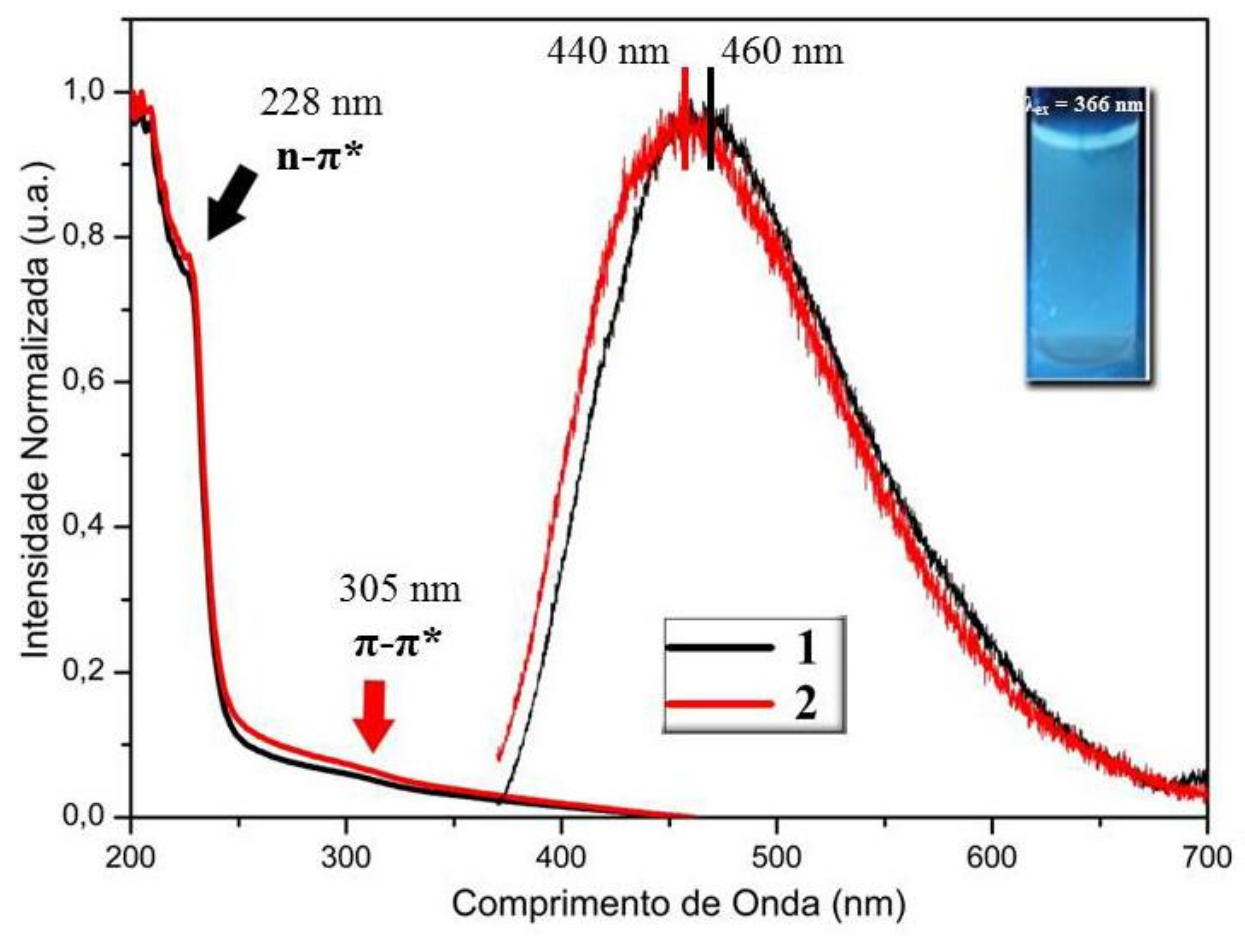

Figura 13- Espectros de absorção no UV-Vis e de emissão dos C-Dots. As linhas em vermelho e preto referem-se a $\mathbf{1}$ e $\mathbf{2}$, respectivamente. Os espectros de emissão foram adquiridos a temperatura ambiente, sob excitação de $300 \mathrm{~nm}$. As setas preta e vermelha indicam as transições $n-\pi^{*}$ e $\pi-\pi^{*}$. A figura anexa mostra 1 sob luz ultravioleta $\left(\lambda_{\mathrm{ex}}=366\right.$ $\mathrm{nm})$.

Os gaps de energia para os dois materiais foram obtidos através do método de Tauc. ${ }^{76}$ Essa metodologia utiliza-se da equação 1 para estimar a diferença de energia entre os orbitais 
desocupado de menor energia e ocupado de maior energia, a partir de espectros de absorção na região do UV-Vis. Na referida equação, $\boldsymbol{\alpha}, \mathrm{E}_{\mathrm{ex}}, \mathrm{E}_{\mathrm{g}}, \mathrm{A}$ e $\mathrm{m}$ são, respectivamente, o coeficiente de absorção do material, as energias da radiação incidente usada na análise de UVVis e do gap de energia, uma constante de proporcionalidade e um número inteiro dependente do tipo de transição eletrônica experimentada pelo material. ${ }^{76}$ No caso dos C-Dots, o valor de m utilizado foi $1 / 2$, supondo-se que a transição sofrida pelos nanomateriais é direta e permitida. A figura 14 contém os gráficos gerados, que levaram à conclusão de que os gaps de energia de 1 e 2, obtidos pelo método de Tauc, são de 5,20 e 5,23 eV, respectivamente. Esses valores estão de acordo com o gap de energia de materiais semelhantes, anteriormente reportados. ${ }^{77} \mathrm{~A}$ discreta diminuição no gap de energia de $\mathbf{1}$, quando comparado a $\mathbf{2}$, é consequência de sua maior oxidação superficial. A equivalência das faixas de distribuição de tamanhos dos dois tipos de nanopartículas contribui para a proximidade entre os valores calculados. ${ }^{35}$

Equação 1- Fórmula usada no método de Tauc

$$
\left(\boldsymbol{\alpha} \cdot \mathrm{E}_{\mathrm{ex}}\right)^{1 / \mathrm{m}}=\mathrm{A}\left(\mathrm{E}_{\mathrm{ex}} \cdot \mathrm{E}_{\mathrm{g}}\right)
$$

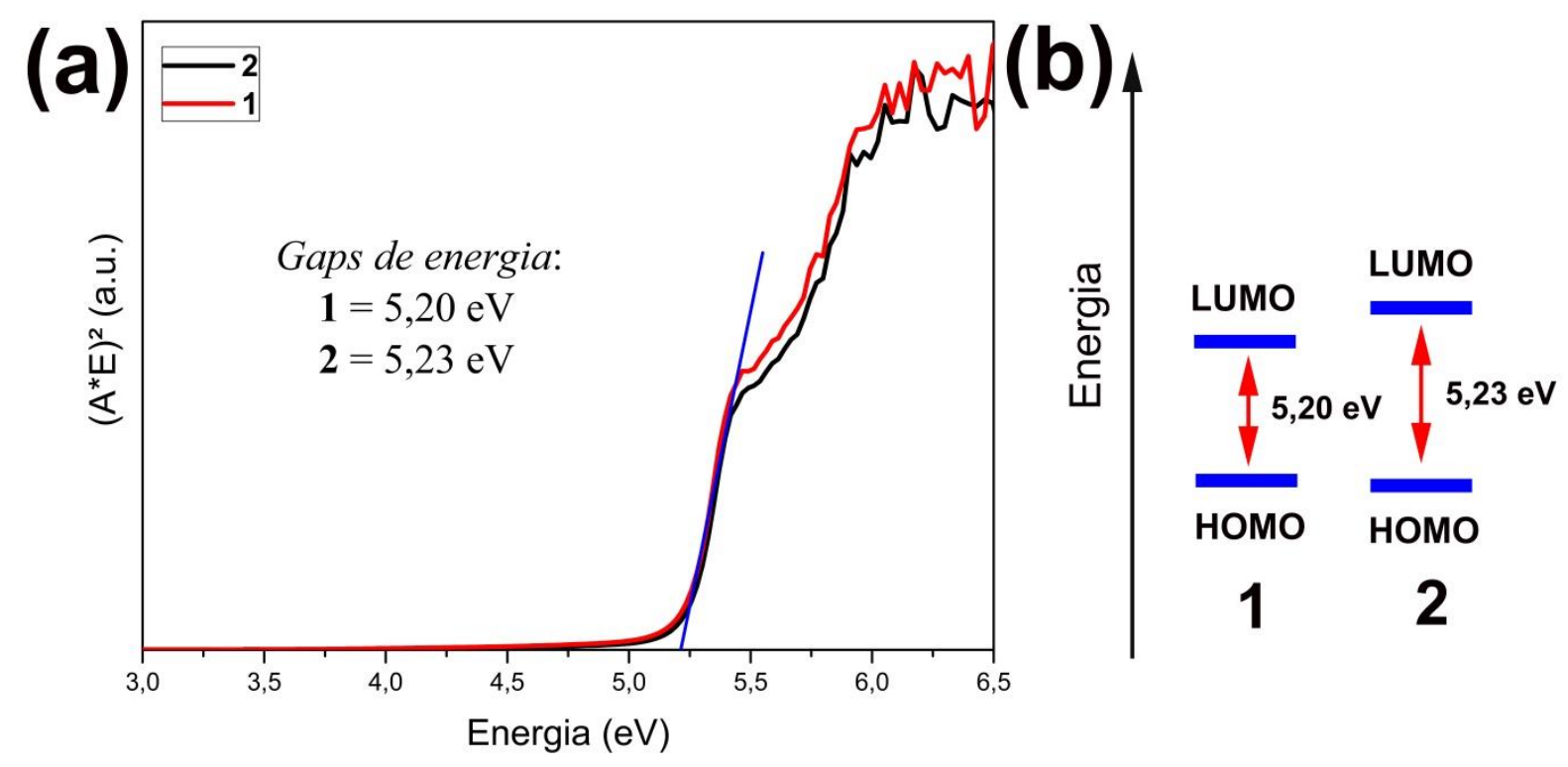

Figura 14- (a) Curvas obtidas a partir do método de Tauc para 1 e 2 . As linhas em vermelho e preto referem-se a 1 e $\mathbf{2}$, respectivamente. (b) Ilustração dos gaps de energia dos materiais.

Na Figura 15 apresentam-se os espectros de emissão dos C-Dots. Os máximos das emissões de 1 e 2 mostraram-se dependentes do comprimento de onda de excitação. Os 
comportamentos espectrais dos materiais são ligeiramente diferentes entre si. Os C-Dots do tipo 1 exibiram um deslocamento para o azul de $20 \mathrm{~nm}(460-440 \mathrm{~nm})$, quando o comprimento de onda de excitação aumentou, gradualmente, de 300 para $340 \mathrm{~nm}$. Já entre 350-450 nm, as bandas de emissão foram deslocadas progressivamente para o vermelho por $66 \mathrm{~nm}$ (440-506 nm). Por outro lado, o comportamento de emissão dependente da energia de excitação de 2 começa apenas a partir da excitação em $350 \mathrm{~nm}$, quando as bandas de emissão sofreram um deslocamento batocrômico de cerca de $70 \mathrm{~nm}$. Esses resultados são consistentes com a presença de diferentes defeitos nas superfícies dos C-Dots, como o resultado líquido dos diferentes graus de oxidação de 1 e 2. ${ }^{62,34}$ A maior variação de comprimento de onda máximo de emissão entre os espectros de $\mathbf{1}$ foi de $10 \mathrm{~nm}$ e de $\mathbf{2}$ foi de $12 \mathrm{~nm}$.
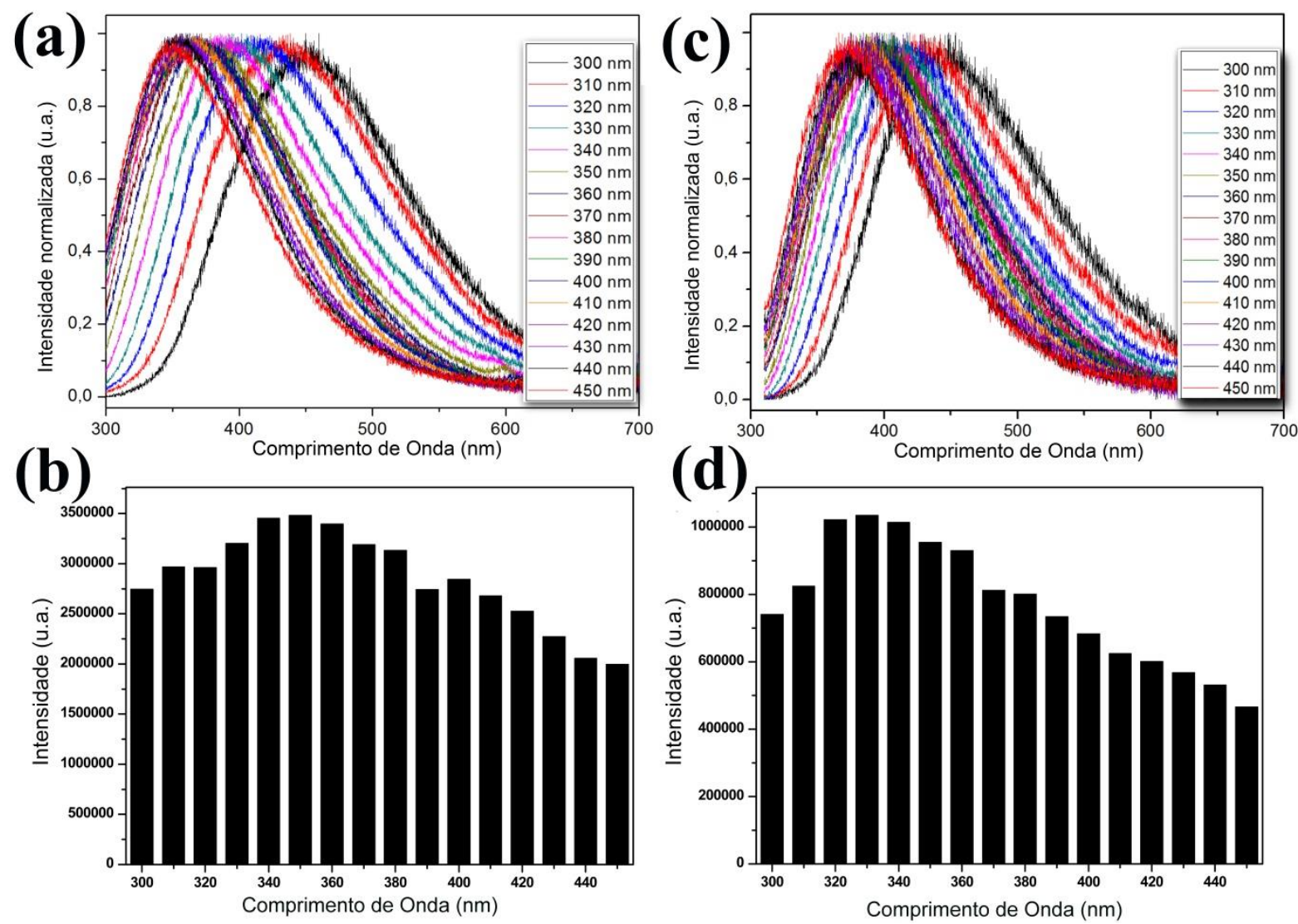

Figura 15- (a) e (c): espectros de emissão de 1 e 2 adquiridos a temperatura ambiente sob comprimentos de onda de excitação progressivamente maiores (de $300 \mathrm{~nm}$ a $450 \mathrm{~nm}$ ); (b) e (d): intensidades de emissão em função do comprimento de onda de excitação de $\mathbf{1}$ e $\mathbf{2}$.

Os C-Dots 1 e 2 possuem comportamentos espectrais distintos, com aumento gradual do $\mathrm{pH}$ (Figura 16). Para os C-Dots do tipo 2, o pH do meio aquoso não afeta drasticamente as intensidades de emissão, isso ocorre devido à menor dependência dos grupos funcionais na 
superfície dos C-Dots em relação ao pH. A variação máxima é de $28 \%$. Por outro lado, a intensidade de emissão de $\mathbf{1}$ diminui quando os valores de $\mathrm{pH}$ aumentam (até $50 \%$ de variação). Esse fenômeno pode ser justificado pela existência de maiores quantidades de grupos carboxílicos nas superfícies das nanopartículas. Em condições ácidas, esses grupos funcionais estão protonados; com aumento gradual do $\mathrm{pH}$, os níveis de Fermi podem ser deslocados devido ao processo de desprotonação. ${ }^{78,79}$
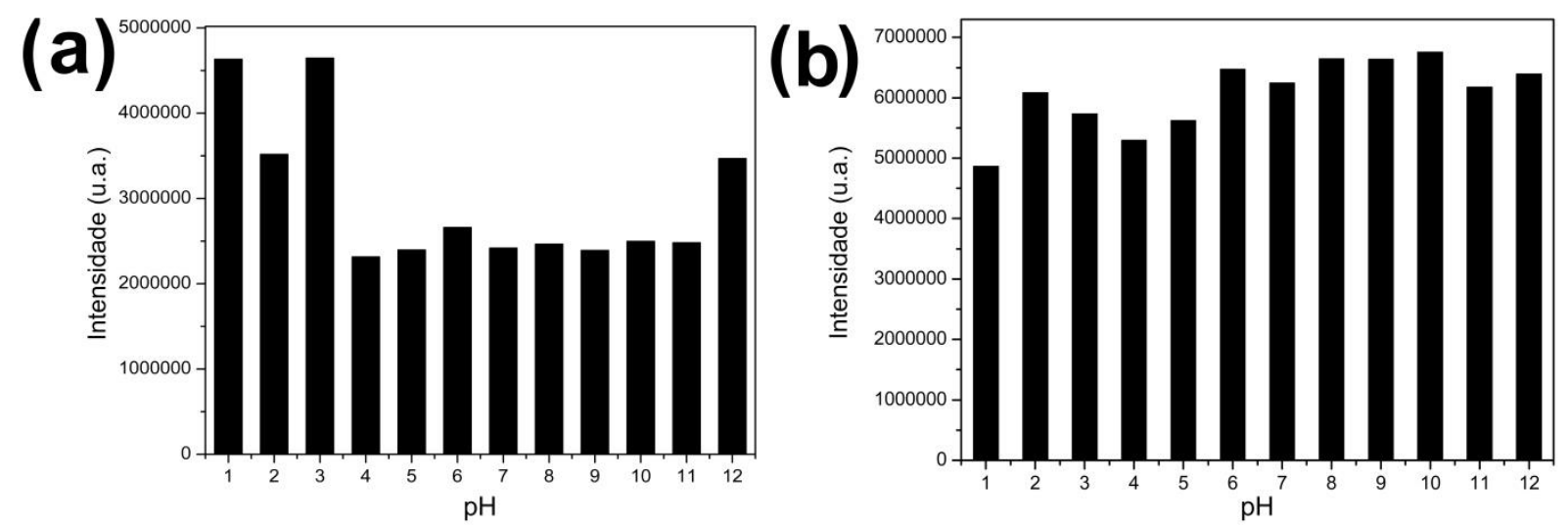

Figura 16- (a) e (b): intensidades de emissão em função do pH de 1 e 2, sob excitação de 300 $\mathrm{nm}$.

O efeito da temperatura sobre as intensidades de emissão dos C-Dots é mostrado na Figura 17. Os comportamentos de 1 e 2 são próximos entre si. As intensidades de emissão de ambos diminuem progressivamente, em consequência do acoplamento multifóton a temperaturas mais elevadas, favorecendo o decaimento não radiativo. ${ }^{17}$
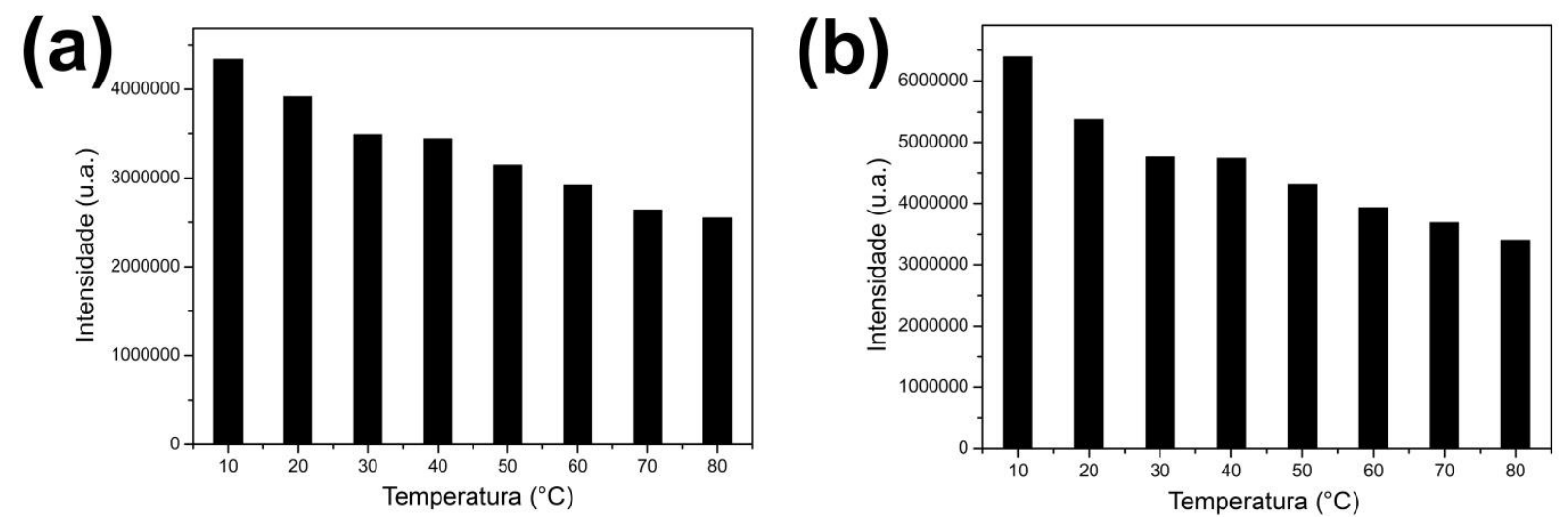

Figura 17- (a) e (b): intensidades de emissão em função da temperatura das soluções de $\mathbf{1}$ e $\mathbf{2}$, sob excitação de $300 \mathrm{~nm}$. 
Os C-Dots 1 e 2 também exibiram interessantes propriedades de UC quando excitados na região do NIR, semelhantes àquelas relatadas para C-Dots produzidos a partir de outras fontes de carbono. ${ }^{24,35,80,81}$ Os espectros de excitação de $\mathbf{1}$ e $\mathbf{2}$ na região do NIR foram adquiridos monitorando suas emissões em $460 \mathrm{~nm}$ (Figura 18) e exibem duas bandas principais centradas em 810 e $850 \mathrm{~nm}$, que devem ser as bandas responsáveis pela excitação dos materiais.

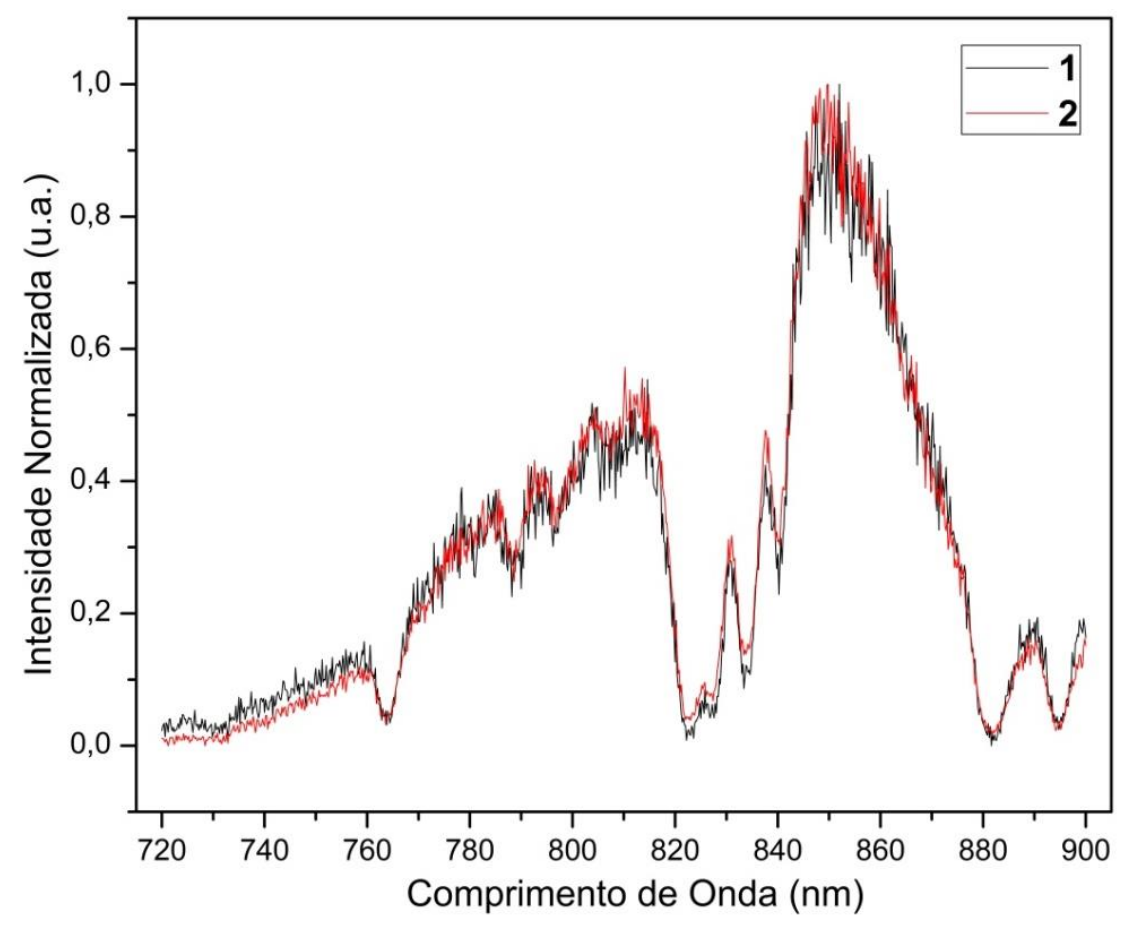

Figura 18- Espectros de excitação de 1 e 2 na região do NIR, adquiridos a temperatura ambiente, monitorando suas emissões em $460 \mathrm{~nm}$.

A Figura 19 mostra os espectros de emissão de UC de $\mathbf{1}$ e $\mathbf{2}$, adquiridos a temperatura ambiente, sob excitação na região do NIR. Os espectros de emissão UC de 1 e 2 mostram bandas largas centradas em 470 e $460 \mathrm{~nm}$, sob excitação de $750 \mathrm{~nm}$. As propriedades de UC de C-Dots, como descrito anteriormente, ainda são um assunto bastante polêmico. Os espectros de emissão de UC mostram emissões dependentes do comprimento de onda de excitação, semelhantemente ao descrito para materiais similares. ${ }^{79}$ Esses resultados tornam nossos nanomateriais de interesse para o desenvolvimento de novos compósitos fotocatalisadores, de células solares, e, especialmente, para aplicações em meios biológicos. ${ }^{23}$ 

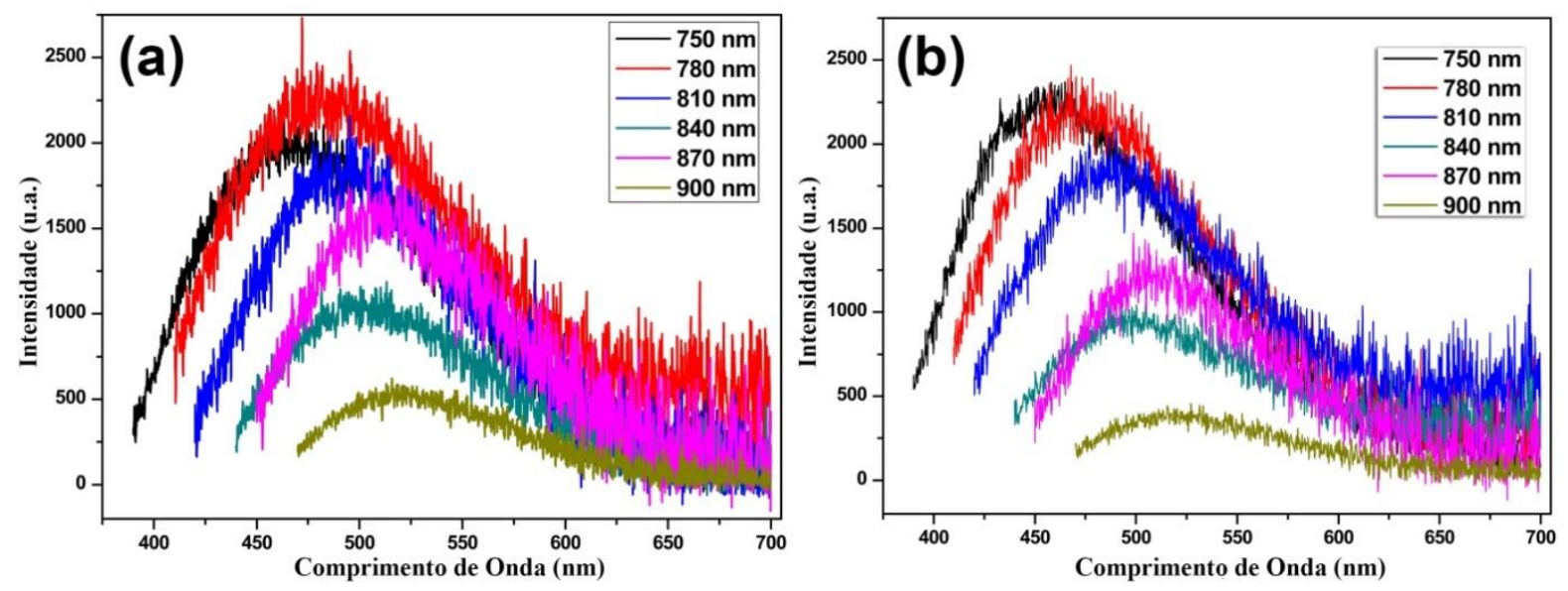

Figura 19-(a) e (b): espectros de emissão de UC de 1 e 2, a temperatura ambiente, $\mathrm{pH}=6$, sob excitação na região do NIR.

Por último, o C-Dots mais oxidados 1 foram submetidos a experimentos de imageamento celular. O motivo da escolha de 1 para os testes foi que os resultados obtidos poderiam ser mais facilmente comparados com experimentos de bioimageamento reportados anteriormente na literatura. Além disso, 1 deve possuir maior quantidade de grupos carboxilato em sua superfície, devido ao maior grau de oxidação a ele imposto pela rota sintética, o que aumenta sua solubilidade em água, quando comparado a 2. A figura 20 exibe as imagens de células de câncer de mama (MCF-7). 

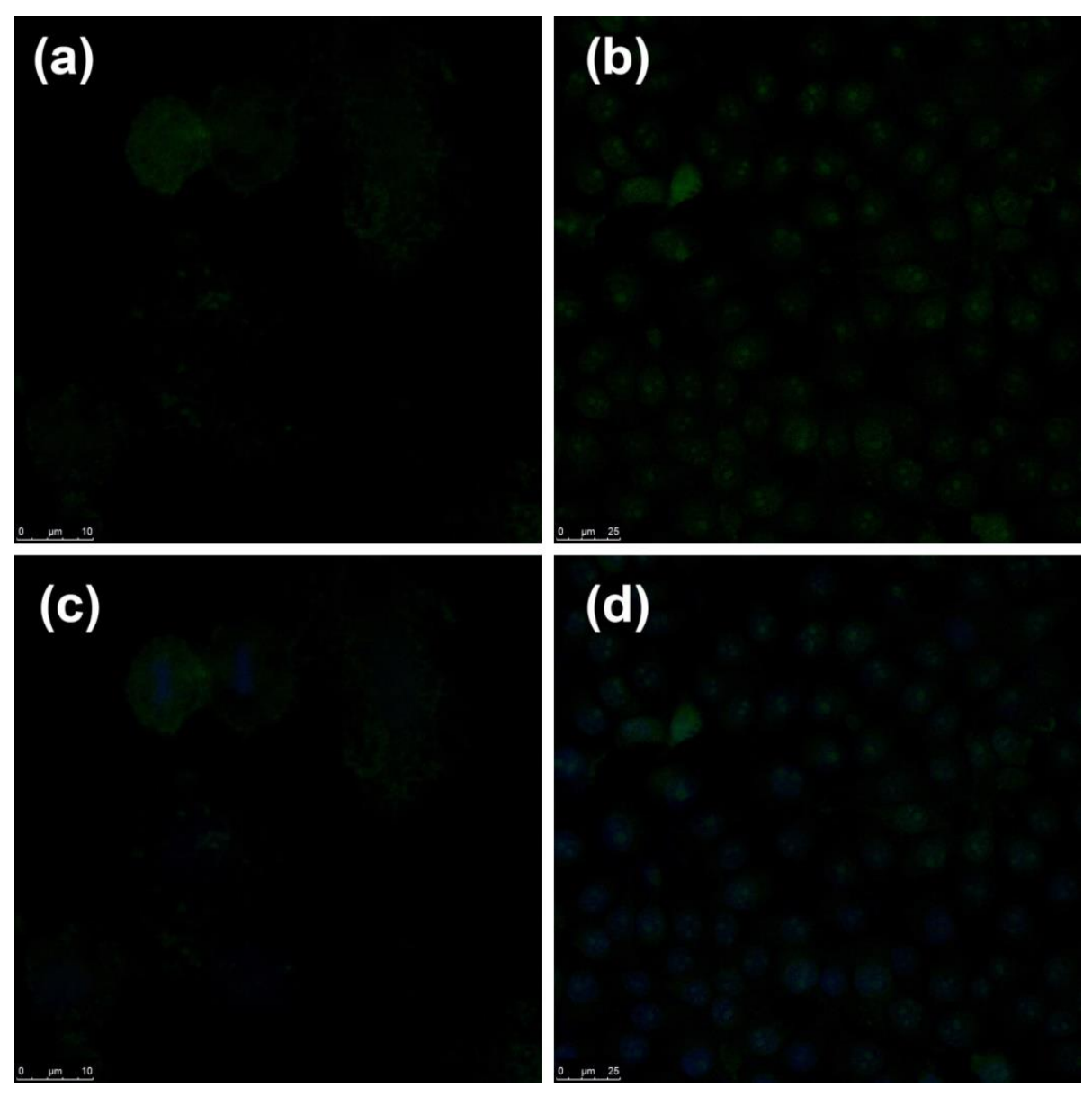

Figura 20- Experimentos de bioimageamento usando os C-dots 1 em células MCF-7 ( $\lambda_{\text {ex }}=$ $405 \mathrm{~nm}$ ). (a) e (b) mostram os padrões de coloração (verde) para células fixadas e vivas, respectivamente. (c) e (d) exibem a sobreposição entre 1 e a coloração do DNA com DAPI.

C-Dots 1 e DAPI são responsáveis pelas emissões verde $\left(\lambda_{\mathrm{em}}=495 \mathrm{~nm}\right)$ e azul, respectivamente. Barras de referência: $10 \mu \mathrm{m}$ para (a) e (c) e $25 \mu \mathrm{m}$ para (b) e (d).

Um padrão de coloração típico de biosondas não seletivas foi observado nos citoplasmas celulares de ambas as amostras (células fixadas e vivas). Observou-se também uma característica muito interessante quando os núcleos das células foram analisados. O sinal de fluorescência é fortemente associado à região do nucléolo nas amostras de células vivas. Isto porque os C-Dots 1 provaram ser capazes de corar os nucléolos, como é mostrado nas figuras 20 (b) e (d). Nucléolos são regiões dos núcleos de alta atividade, e que contêm vários complexos enzimáticos que desempenham papéis fundamentais na homeostase celular. ${ }^{82} \mathrm{~A}$ consequência disso é a diferente composição química dessa região, o que permitiu o maior acúmulo dos C-Dots. As amostras de células vivas e fixadas também mostraram uma ligeira coloração associada à região do citoplasma, próxima aos núcleos. Entretanto, a coloração dos nucléolos é bem mais intensa, e não se confunde com a fluorescência do citoplasma. A 
importância destes resultados é que existem poucas substâncias capazes de marcar o nucléolo das células. A maioria delas é constituída de corantes orgânicos de alto custo e que exigem condições específicas de armazenamento, ${ }^{83}$ ao contrário de nossos nanomateriais. Kang e colaboradores reportaram um comportamento semelhante, também para materiais carbonáceos, em experimentos de bioimageamento com células HeLa. ${ }^{84}$

$\mathrm{O}$ estudo relatado nesta dissertação foi publicado por nosso grupo recentemente. ${ }^{85} \mathrm{O}$ texto do artigo em questão encontra-se em anexos. 


\section{Conclusões}

C-Dots foram produzidos, com êxito, a partir de bagaço de malte através de duas rotas sintéticas distintas. As nanopartículas resultantes apresentaram boa solubilidade aquosa e propriedades ópticas de alto interesse para as mais diversas destinações. As sínteses aqui reportadas transformam matéria-prima de baixo valor agregado em materiais de alta tecnologia e são uma possibilidade para a melhoria da sustentabilidade do processo de produção de cerveja.

Os nanomateriais mostraram-se estruturalmente semelhantes entre si, como demonstraram os experimentos de MET, IV e espectroscopia Raman. Todavia, suas propriedades espectroscópicas manifestaram diferenças condizentes com seus distintos graus de oxidação superficial impostos pelas rotas de síntese.

Os C-Dots 1 foram escolhidos para serem testados em experimentos de bioimageamento em células MCF-7. O resultado foi uma maior acumulação das partículas na região do nucléolo celular. Esse comportamento demonstra a potencialidade de $\mathbf{1}$ para utilização em experiências envolvendo imageamento celular e fornece uma nova ferramenta para estudos nucleares. Vale ressaltar que existem poucas moléculas disponíveis comercialmente capazes de corar o nucléolo celular seletivamente.

Ademais, a fotoluminescência UC apresentada pelos C-Dots confere-lhes potencial tanto para uso no desenvolvimento de novos compósitos fotocatalisadores e células solares, quanto para aplicações em meio biológico como aquelas envolvendo imageamento celular por microscopia de fluorescência, por exemplo. 


\section{Perspectivas}

Os resultados reportados nesta dissertação demonstram o potencial dos C-Dots produzidos a partir de bagaço de malte para as mais diversas aplicações, inclusive para o carreamento de fármacos.

Por outro lado, a leishmaniose é uma das doenças que afligem países de climas tropicais e subtropicais e já foi classificada pela Organização Mundial de Saúde (OMS) como uma das mais negligenciadas do mundo. ${ }^{86}$ No Brasil, os casos de leishmaniose estão distribuídos por quatro das cinco regiões geográficas, ${ }^{87}$ e, sem dúvidas, é um problema de saúde pública.

Os fármacos mais amplamente utilizados contra a leishmaniose são os antimoniais, que têm como limitação a alta toxicidade ao ser humano. Além desses, formulações de Anfotericina B (AnB) são usadas especialmente em casos de Leishmania resistente aos antimoniais e em pacientes com sistema imunológico comprometido, ${ }^{88}$ apesar de essas formulações apresentarem altos preço e toxicidade. ${ }^{89}$

Sem dúvidas, o tratamento da leishmaniose carece de soluções que atendam às necessidades das regiões mais pobres do mundo, onde essa doença é um problema. A alta toxicidade dos remédios com valores acessíveis aumenta os índices de desistência do tratamento e mortalidade da doença. Outro fator que compromete as taxas de cura das infecções causadas pela Leishmania é a dificuldade na diagnose da doença que leva à sua detecção tardia. $^{90}$

Os recém-descobertos C-Dots vêm sendo usados, com sucesso, no carreamento de fármacos. ${ }^{50}$ Esses nanomateriais são inertes quimicamente e não tóxicos em condições fisiológicas. ${ }^{52}$ Nossa proposta é avaliar, futuramente, a eficácia e a toxicidade de formulações que utilizem C-Dots no carreamento de antimoniais e AnB. Ambicionamos, também, investigar a possibilidade de utilização dessas formulações na diagnose da doença. 


\section{Referências}

(1) Kroto, H. W.; Heath, J. R.; O'Brien, S. C.; Curl, R. F.; Smalley, R. E. Nature 1985, 318,

162.

(2) Iijima, S. Nature 1991, 354, 56.

(3) Novoselov, K. S.; Geim, A. K.; Morozov, S.; Jiang, D.; Zhang, Y.; Dubonos, S. a.; Grigorieva, I.; Firsov, A. science 2004, 306, 666.

(4) Hong, G.; Diao, S.; Antaris, A. L.; Dai, H. Chemical reviews 2015.

(5) Xu, X.; Ray, R.; Gu, Y.; Ploehn, H. J.; Gearheart, L.; Raker, K.; Scrivens, W. A. Journal of the American Chemical Society 2004, 126, 12736.

(6) Baker, S. N.; Baker, G. A. Angewandte Chemie International Edition 2010, 49, 6726.

(7) Yang, Z.-C.; Wang, M.; Yong, A. M.; Wong, S. Y.; Zhang, X.-H.; Tan, H.; Chang, A. Y.; Li, X.; Wang, J. Chemical communications 2011, 47, 11615.

(8) Liu, C.; Zhang, P.; Tian, F.; Li, W.; Li, F.; Liu, W. J. Mater.Chem. 2011, 21, 13163.

(9) Liu, R.; Wu, D.; Feng, X.; Muillen, K. Journal of the American Chemical Society 2011, 133,

15221.

(10) Bourlinos, A. B.; Stassinopoulos, A.; Anglos, D.; Zboril, R.; Karakassides, M.; Giannelis, E. P. Small 2008, 4, 455.

(11) Zhao, Q.-L.; Zhang, Z.-L.; Huang, B.-H.; Peng, J.; Zhang, M.; Pang, D.-W. Chem. Commun. 2008, 5116.

(12) Lu, J.; Yeo, P. S. E.; Gan, C. K.; Wu, P.; Loh, K. P. Nature nanotechnology 2011, 6, 247.

(13) Tao, H.; Yang, K.; Ma, Z.; Wan, J.; Zhang, Y.; Kang, Z.; Liu, Z. Small 2012, 8, 281.

(14) Peng, J.; Gao, W.; Gupta, B. K.; Liu, Z.; Romero-Aburto, R.; Ge, L.; Song, L.; Alemany, L. B.; Zhan, X.; Gao, G. Nano letters 2012, 12, 844.

(15) Zhou, J.; Sheng, Z.; Han, H.; Zou, M.; Li, C. Materials Letters 2012, 66, 222.

(16) Liu, S.-S.; Wang, C.-F.; Li, C.-X.; Wang, J.; Mao, L.-H.; Chen, S. Journal of Materials Chemistry C 2014, 2, 6477.

(17) D'Angelis do ES, B.; Corrêa, J. R.; Medeiros, G. A.; Barreto, G.; Magalhães, K. G.; de Oliveira, A. L.; Spencer, J.; Rodrigues, M. O.; Neto, B. A. Chemistry-A European Journal 2015, 21, 5055.

(18) Sahu, S.; Behera, B.; Maiti, T. K.; Mohapatra, S. Chemical communications 2012, 48, 8835.

(19) De, B.; Karak, N. Rsc Advances 2013, 3, 8286.

(20) Park, S. Y.; Lee, H. U.; Park, E. S.; Lee, S. C.; Lee, J.-W.; Jeong, S. W.; Kim, C. H.; Lee, Y.-C.; Huh, Y. S.; Lee, J. ACS applied materials é interfaces 2014, 6, 3365.

(21) Wu, L.; Cai, X.; Nelson, K.; Xing, W.; Xia, J.; Zhang, R.; Stacy, A. J.; Luderer, M.; Lanza, G. M.; Wang, L. V. Nano research 2013, 6, 312.

(22) Wu, Z. L.; Zhang, P.; Gao, M. X.; Liu, C. F.; Wang, W.; Leng, F.; Huang, C. Z. Journal of Materials Chemistry B 2013, 1, 2868.

(23) Li, H.; Kang, Z.; Liu, Y.; Lee, S.-T. Journal of Materials Chemistry 2012, 22, 24230.

(24) Cao, L.; Wang, X.; Meziani, M. J.; Lu, F.; Wang, H.; Luo, P. G.; Lin, Y.; Harruff, B. A.; Veca, L. M.; Murray, D. Journal of the American Chemical Society 2007, 129, 11318.

(25) Shen, J.; Zhu, Y.; Yang, X.; Li, C. Chemical communications 2012, 48, 3686.

(26) Zheng, L.; Chi, Y.; Dong, Y.; Lin, J.; Wang, B. Journal of the American Chemical Society $2009,131,4564$.

(27) Sun, Y.-P.; Zhou, B.; Lin, Y.; Wang, W.; Fernando, K. S.; Pathak, P.; Meziani, M. J.; Harruff, B. A.; Wang, X.; Wang, H. Journal of the American Chemical Society 2006, 128, 7756.

(28) Liu, R.; Wu, D.; Liu, S.; Koynov, K.; Knoll, W.; Li, Q. Angewandte Chemie 2009, 121, 4668.

(29) Wang, X.; Qu, K.; Xu, B.; Ren, J.; Qu, X. Journal of Materials Chemistry 2011, $21,2445$.

(30) Pan, D.; Zhang, J.; Li, Z.; Wu, M. Advanced Materials 2010, 22, 734.

(31) Ray, S. C.; Saha, A.; Jana, N. R.; Sarkar, R. The Journal of Physical Chemistry C 2009, 113,

18546 
(32) Tian, L.; Ghosh, D.; Chen, W.; Pradhan, S.; Chang, X.; Chen, S. Chemistry of materials 2009, 21, 2803.

(33) Fang, Y.; Guo, S.; Li, D.; Zhu, C.; Ren, W.; Dong, S.; Wang, E. ACS nano 2011, 6, 400.

(34) Zhu, S.; Zhang, J.; Tang, S.; Qiao, C.; Wang, L.; Wang, H.; Liu, X.; Li, B.; Li, Y.; Yu, W. Advanced Functional Materials 2012, 22, 4732.

(35) Li, H.; He, X.; Kang, Z.; Huang, H.; Liu, Y.; Liu, J.; Lian, S.; Tsang, C. H. A.; Yang, X.; Lee, S. T. Angewandte Chemie International Edition 2010, 49, 4430.

(36) Eda, G.; Lin, Y. Y.; Mattevi, C.; Yamaguchi, H.; Chen, H. A.; Chen, I.; Chen, C. W.; Chhowalla, M. Advanced Materials 2010, 22, 505.

(37) Li, H.; Ming, H.; Liu, Y.; Yu, H.; He, X.; Huang, H.; Pan, K.; Kang, Z.; Lee, S.-T. New Journal of Chemistry 2011, 35, 2666.

(38) Ma, Z.; Ming, H.; Huang, H.; Liu, Y.; Kang, Z. New Journal of Chemistry 2012, 36, 861.

(39) Shen, J.; Zhu, Y.; Chen, C.; Yang, X.; Li, C. Chemical communications 2011, 47, 2580.

(40) Wang, F.; Xie, Z.; Zhang, B.; Liu, Y.; Yang, W.; Liu, C.-y. Nanoscale 2014, 6, 3818.

(41) Wen, X.; Yu, P.; Toh, Y.-R.; Ma, X.; Tang, J. Chemical communications 2014, $50,4703$.

(42) Zhang, Y.; He, J. Physical Chemistry Chemical Physics 2015, 17, 20154.

(43) Li, Y.; Hu, Y.; Zhao, Y.; Shi, G.; Deng, L.; Hou, Y.; Qu, L. Advanced Materials 2011, 23, 776.

(44) Wang, X.; Cao, L.; Lu, F.; Meziani, M. J.; Li, H.; Qi, G.; Zhou, B.; Harruff, B. A.;

Kermarrec, F.; Sun, Y.-P. Chemical communications 2009, 3774.

(45) Zhou, L.; Lin, Y.; Huang, Z.; Ren, J.; Qu, X. Chemical communications 2012, 48, 1147.

(46) Liu, L.; Li, Y.; Zhan, L.; Liu, Y.; Huang, C. Science China Chemistry 2011, 54, 1342.

(47) Pan, D.; Guo, L.; Zhang, J.; Xi, C.; Xue, Q.; Huang, H.; Li, J.; Zhang, Z.; Yu, W.; Chen, Z. Journal of Materials Chemistry 2012, 22, 3314.

(48) Huang, P.; Lin, J.; Wang, X.; Wang, Z.; Zhang, C.; He, M.; Wang, K.; Chen, F.; Li, Z.; Shen, G. Advanced Materials 2012, 24, 5104.

(49) LeCroy, G. E.; Sonkar, S. K.; Yang, F.; Veca, L. M.; Wang, P.; Tackett, K. N.; Yu, J.-J.; Vasile, E.; Qian, H.; Liu, Y. ACS nano 2014, 8, 4522.

(50) Tang, J.; Kong, B.; Wu, H.; Xu, M.; Wang, Y.; Wang, Y.; Zhao, D.; Zheng, G. Advanced Materials 2013, 25, 6569.

(51) Liu, Z.; Robinson, J. T.; Sun, X.; Dai, H. Journal of the American Chemical Society 2008, 130,

10876.

(52) Zhu, S.; Zhang, J.; Qiao, C.; Tang, S.; Li, Y.; Yuan, W.; Li, B.; Tian, L.; Liu, F.; Hu, R. Chem. Commun. 2011, 47, 6858.

(53) Loh, K. P.; Bao, Q.; Eda, G.; Chhowalla, M. Nature chemistry 2010, 2, 1015.

(54) Chan, W. C.; Maxwell, D. J.; Gao, X.; Bailey, R. E.; Han, M.; Nie, S. Current opinion in biotechnology 2002, 13, 40.

(55) Bamforth, C. Beer: tap into the art and science of brewing; Oxford University Press, 2009.

(56) Mardegan, S. F.; Andrade, T. M. B.; de Sousa Neto, E. R.; de Castro Vasconcellos, E. B.;

Martins, L. F. B.; Mendonça, T. G.; Martinelli, L. A. Journal of food composition and analysis 2013, $29,52$.

(57) dos Santos Mathias, T. R.; de Mello, P. P. M.; ervulo, E. F. C. Journal of Brewing and Distilling 2014, 5 , 1 .

(58) Cordeiro, L. G.; El-Aouar, Â. A.; de Araújo, C. V. B. Journal of thermal analysis and calorimetry 2013, 112, 713 .

(59) MATHIAS, T.; de MELLO, P.; SERVULO, E. Blucher Chemical Engineering Proceedings

$2015,1,3805$

(60) Brust, L. A. C.; Aragão, A. P.; Júnior, P. S. B.; Galvão, A.; França, T. N.; Graça, F. A.; Peixoto, P. V. Pesquisa Veterinária Brasileira 2015, 35, 956.

(61) Mello, L. R.; Mali, S. Industrial Crops and Products 2014, 55, 187.

(62) Bao, L.; Zhang, Z. L.; Tian, Z. Q.; Zhang, L.; Liu, C.; Lin, Y.; Qi, B.; Pang, D. W. Advanced Materials 2011, 23, 5801 .

(63) Zhu, S.; Zhang, J.; Liu, X.; Li, B.; Wang, X.; Tang, S.; Meng, Q.; Li, Y.; Shi, C.; Hu, R. Rsc Advances 2012, 2, 2717. 
(64) Wu, L.; Luderer, M.; Yang, X.; Swain, C.; Zhang, H.; Nelson, K.; Stacy, A. J.; Shen, B.; Lanza, G. M.; Pan, D. Theranostics 2013, 3, 677.

(65) Lotya, M.; Hernandez, Y.; King, P. J.; Smith, R. J.; Nicolosi, V.; Karlsson, L. S.; Blighe, F. M.; De, S.; Wang, Z.; McGovern, I. Journal of the American Chemical Society 2009, 131, 3611.

(66) Krishnamoorthy, K.; Veerapandian, M.; Yun, K.; Kim, S.-J. Carbon 2013, 53, 38.

(67) Wang, G.; Yang, J.; Park, J.; Gou, X.; Wang, B.; Liu, H.; Yao, J. The Journal of Physical Chemistry C 2008, 112, 8192.

(68) Holler, F. J.; Skoog, D. A.; Crouch, S. R.; Pasquini, C. Princípios de análise instrumental; Bookman, 2009.

(69) Hu, S.-L.; Niu, K.-Y.; Sun, J.; Yang, J.; Zhao, N.-Q.; Du, X.-W. Journal of Materials Chemistry 2009, 19, 484.

(70) Yadav, R. M.; Dobal, P. S.; Shripathi, T.; Katiyar, R.; Srivastava, O. Nanoscale research letters 2009, 4, 197.

(71) Rousseau, D.; Miller, R.; Leroi, G. The Journal of Chemical Physics 1968, 48, 3409.

(72) Hsu, P.-C.; Chang, H.-T. Chemical communications 2012, 48, 3984.

(73) Wu, M.; Wang, Y.; Wu, W.; Hu, C.; Wang, X.; Zheng, J.; Li, Z.; Jiang, B.; Qiu, J. Carbon $2014,78,480$.

(74) Bagga, K.; McCann, R.; Wang, M.; Stalcup, A.; Vazquez, M.; Brabazon, D. Journal of colloid and interface science 2015, 447, 263.

(75) Hsu, P.-C.; Shih, Z.-Y.; Lee, C.-H.; Chang, H.-T. Green Chemistry 2012, 14, 917.

(76) Tauc, J.; Abeles, F. 1972, 372.

(77) Zhou, J.; Booker, C.; Li, R.; Zhou, X.; Sham, T.-K.; Sun, X.; Ding, Z. Journal of the American Chemical Society 2007, 129, 744.

12418.

(78) Zhao, W.; Song, C.; Pehrsson, P. E. Journal of the American Chemical Society 2002, 124,

(79) Jia, X.; Li, J.; Wang, E. Nanoscale 2012, 4, 5572.

(80) Zhuo, S.; Shao, M.; Lee, S.-T. ACS nano 2012, 6, 1059.

(81) Yin, B.; Deng, J.; Peng, X.; Long, Q.; Zhao, J.; Lu, Q.; Chen, Q.; Li, H.; Tang, H.; Zhang, Y. Analyst 2013, 138, 6551.

(82) Shaw, P. J. eLS 2011.

(83) Haugland, R. Invitrogen, Carlsbad 2005, 11.

(84) Kong, W.; Liu, R.; Li, H.; Liu, J.; Huang, H.; Liu, Y.; Kang, Z. Journal of Materials Chemistry B 2014, 2, 5077.

(85) Rodrigues, C. V.; Correa, J. R.; Aiube, C. M.; Andrade, L. P.; Galvão, P. M.; Costa, P. A.; Campos, A. L.; Pereira, A. J.; Ghesti, G. F.; Felix, J. F. J. Braz. Chem. Soc 2015, 26, 2623.

(86) Faiza, S.; Asmae, H.; Fatima, A.; Afafe, F.; Bouchra, D.; Ibrahim, A.; Abderrahim, S.; Khalid, H.; Mohamed, R.; Hajiba, F. Acta tropica 2015, 149, 106.

(87) Santos, D. O.; Coutinho, C. E.; Madeira, M. F.; Bottino, C. G.; Vieira, R. T.; Nascimento, S. B.; Bernardino, A.; Bourguignon, S. C.; Corte-Real, S.; Pinho, R. T. Parasitology research $2008,103,1$.

(88) Rath, S.; Trivelin, L. A.; Imbrunito, T. R.; Tomazela, D. M.; de Jesús, M. N.; Marzal, P. C.; de Andrade, H.; Tempone, A. G. Química nova 2003, 26, 550.

(89) Barwicz, J.; Christian, S.; Gruda, I. Antimicrobial Agents and Chemotherapy 1992, 36, 2310.

(90) Berman, J. Clinical infectious diseases 1997, 24, 684. 


\title{
8. Anexos
}

doi number

J. Braz Chem. Soc, Vol, 00, No 00, 1-6, 2015. Article

\section{Down- and Up-Conversion Photoluminescence of Carbon-Dots from Brewing Industry Waste: Application in Live Cell-Imaging Experiments}

\author{
Carime V. Rodrigues, ${ }^{*, a}$ José R. Correa,${ }^{b}$ Carlos M. Aiube,${ }^{a}$ Lorena P. Andrade,${ }^{b}$ Pedro M. Galvão ${ }^{a}$ \\ Pâmela A. Costa, ${ }^{a}$ Ariadna L. Campos,${ }^{a}$ Anderson J. Pereira,${ }^{c}$ Grace F. Ghesti, ${ }^{d}$ Jorlandio F. Felix, ${ }^{c, c}$ \\ Ingrid T. Weber, ${ }^{a}$ Brenno A. Neto ${ }^{b}$ and Marcelo O. Rodrigues ${ }^{a}$
}

\author{
${ }^{a}$ Laboratório de Inorgânica e Materiais (LIMA), Instituto de Química (IQ), ${ }^{b}$ Laboratório de

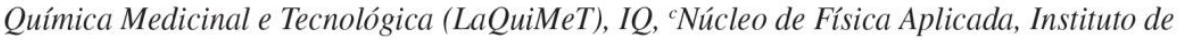 \\ Física (IF) and 'Laboratório de Catálise (LABCAT), IQ, Universidade de Brasília (UnB), \\ Campus Universitário Darcy Ribeiro, 70904-970 Brasilia-DF, Brazil
}

eDepartamento de Física, Universidade Federal de Viçosa (UFV), 36570-900 Viçosa-MG, Brazil

Simple synthetic procedures have been applied to obtain luminescent carbon quantum dots, also referred as C-dots, from an abundant carbon source, that is, from the brewing industry waste The synthetic procedures have been conducted aiming to investigate the effects of the oxidation stage on the properties of the nanomaterial. C-dots down- and up-conversion properties, as well as their potential for cellular imaging experiments in live (and adhered) cells, are disclosed herein.

Keywords: C-dots, luminescence, up-conversion, live cell-imaging

\section{Introduction}

The development of new photoluminescent nanomaterials has attracted much attention over the last decades because of their advantageous properties in comparison to those presented by conventional bulk materials. These nanomaterials have a tremendous impact over a wide range of strategic fields, such as diagnostic, therapeutic, electronic, photonic and energy. ${ }^{1}$ Among well-established fluorescent nanomaterials, the class of the so-called quantum dots (QDs), based on heavy metal elements, may be considered as one of the most iconic and prominent materials. ${ }^{2}$ Heavy metal QDs exhibit attractive properties, such as tunable emission, photostability and intense bright luminescence, which enable them to be widely explored in both medicine and biology. The presence of toxic elements, such as cadmium, lead or mercury in their compositions has been considered, however, as a huge drawback for furthering their applications as a topic of major concerns.

Carbon quantum dots (known as C-dots) are a new class of fluorescent nanoparticles, which have emerged as a promising alternative to overcome major negative aspects

*e-mail: carime.v.rodrigues@gmail.com associated with heavy QDs. C-dots have received a special attention, not only because of their optical properties, but also for both their small size and non-toxicity. These features also open a wealth of possibilities toward the development of new optical probes for biological applications. ${ }^{3,4}$

C-dots spectroscopic properties are the subject of many controversies and some mechanisms have been speculated to be responsible for the luminescence of these materials. The presence of energy traps on their surface, which may cause a quantum confinement effect; the energy states associated to edge defects; or even exciton transitions are some possibilities hotly debated. ${ }^{3}$

C-dots can be produced from a variety of synthetic procedures and from a large range of cheap and readily available carbon sources, such as glucose, watermelon rinds, ${ }^{5}$ hair ${ }^{6}$ and even cow manure. ${ }^{7}$ Wort bagasse is a byproduct from brewing process and is a component of the solid material produced from wort filtration before the next steps toward beer manufacture. ${ }^{8}$ This byproduct is mainly constituted of leftover peels and pulp of malt, grain and also some additives (wheat, rice and corn, for exemple). Crushed malt is $85 \%$ of the total product generated by the brewing industry and is, thus, the most abundant byproduct from this process. ${ }^{9}$ Brazil is the third largest beer producer in the world, with a production of 12.6 million liters (ML) 
while China (40 ML) and the United States (35 ML) have a larger production. ${ }^{8}$

Knowing that brewing residues are admittedly an abundant carbon source, this work aims to explore these materials to synthesize C-dots. We also describe the nanomaterial characterization, down- and up-conversion photoluminescent properties of C-dots obtained through two different methodologies, which are expected to afford C-dots with distinct oxidation degrees. The impact of $\mathrm{pH}$ and temperature over the optical properties were also analyzed. The new synthesized C-dots also had their potential for bioimaging experiments using breast cancer cell (MCF-7) lineages tested. Herein, the newly synthesized nanomaterials are designated as $\mathbf{1}$ and $\mathbf{2}$, referring to the more oxidized and less oxidized $\mathrm{C}$-dots, respectively.

\section{Experimental}

C-dots 1 were obtained similarly to a previously reported methodology, ${ }^{7}$ that is, by chemical oxidation followed by extraction. C-dots $\mathbf{2}$ were synthesized using a similar methodology, but excluding the oxidation treatment (Scheme 1; a detailed procedure can be found in the Supplementary Information file).
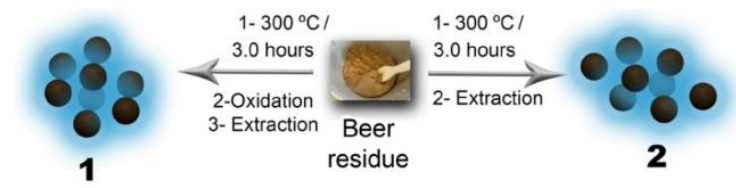

Scheme 1. Synthetic procedures for the synthesis of the studied C-dots 1 and 2.

The high-resolution transmission electron microscopy (HRTEM) images were obtained in a JEOL JEM 2100 electron microscope (Tokyo, Japan) operating at an accelerating voltage of $200 \mathrm{kV}$. The aqueous solutions containing the C-dots were deposited on a 400-mesh C-coated copper grid (Ted Pella Inc., Redding, CA, USA) and dried in air. The Fourier transform infrared (FTIR) spectra were recorded from potassium bromide $(\mathrm{KBr})$ pellets, in a spectral range of $4000-400 \mathrm{~cm}^{-1}$, using a Jasco FT/IR-4100 spectrometer (Tokyo, Japan). The zeta potentials were measured using a Zetasizer Nano-ZS90 (Malvern, United Kingdom). The Raman measurements were performed using the Renishaw InVia micro-Raman system (Sheffield, UK) equipped with the $514.5 \mathrm{~nm}$ argon laser line and a $50 \times$ objective, resulting in a laser spot size of around $1 \mu \mathrm{m}$ in the focal plane. The laser excitation power was about $0.05 \mathrm{~mW}$ at the sample surfaces. The Raman measurements were recorded using $\mathrm{C}$-dots in their powdered form. The fluorescence spectra of the nanomaterials were acquired using a Lumina fluorescence spectrometer (Thermo Ficher Scientific Inc., Waltham, MA, USA) with a Peltier system to vary the temperature, when necessary. A detailed procedure for the cell-imaging experiments is described in the Supplementary Information file.

\section{Results and Discussion}

Brewing residue is an abundant carbon source, considering it is generated in the brewery stage in the beer manufacturing, affording a residue which mainly consists of insoluble proteins, cellulose and lignin. In view of the annual generation of large quantities of this product, for each $100 \mathrm{~L}$ of beer production $40 \mathrm{~kg}$ of wort bagasse are produced, we have decided to explore this waste carbon source to synthesize $\mathrm{C}$-dots. The oxidation degree of $\mathrm{C}$-dots surface is known to be influenced by the synthetic route. ${ }^{10}$ The oxidation process provides $\mathrm{sp}^{3}$ domain formation on the C-dots surface, resulting in surface decoration with different functional groups, such as carboxyl, carbonyl, hydroxyl and epoxy groups. ${ }^{11}$ The presence of these oxygenated functional groups plays important roles on the hydrophilic properties of the $\mathrm{C}$-dot derivatives and also permits the design of more specific bioprobes through simple chemical modifications. ${ }^{7}$ The zeta potential values, acquired at $\mathrm{pH} 5$ in aqueous medium, are in the range of -13.3 and $-8.89 \mathrm{mV}$ for $\mathbf{1}$ and $\mathbf{2}$, respectively, which are comparable to previous reported values. ${ }^{12,13}$ The decrease of zeta potential observed for $\mathbf{2}$ supports the hypothesis that the surface of $\mathbf{1}$ is more oxidized and the presence of carboxylate $\left(\mathrm{COO}^{-}\right)$groups is in accordance with the idea of a higher oxidation level for $\mathbf{1} .^{14}$

High-resolution transmission electron microscopy images acquired for $\mathbf{1}$ and $\mathbf{2}$ (Figure 1) show well-dispersed particles with spheroidal morphologies. $\mathbf{1}$ and $\mathbf{2}$ present narrow size distributions ranging from $2.5-5.9 \mathrm{~nm}$ and $2.5-5.3 \mathrm{~nm}$, with average sizes of 4.08 and $3.72 \mathrm{~nm}$, respectively. The inserts in Figures 1a and 1b exhibit representative images of individual particles, indicating the high crystallinity with lattice parameters of 3.13 and $3.15 \AA$, which correspond to the (002) diffraction plane of graphite. ${ }^{15}$ These results show that both synthetic routes result in uniform C-dots nanoparticles with similar size distributions.

The FTIR spectra (Figure S1) of C-dots $\mathbf{1}$ and $\mathbf{2}$ show an intense absorption band centered at $3450 \mathrm{~cm}^{-1}$ assigned to $\mathrm{O}-\mathrm{H}$ bonds stretching vibrations. The bands centered at $1630 \mathrm{~cm}^{-1}$ were attributed to asymmetrical vibrations of the $\mathrm{C}=\mathrm{O}$ groups and these at $1380 \mathrm{~cm}^{-1}$ assigned to the $\mathrm{C}-\mathrm{H}$ bending.

Raman spectroscopy provides a powerful diagnostic tool to examine crystallinity. ${ }^{16}$ The Raman scattering 

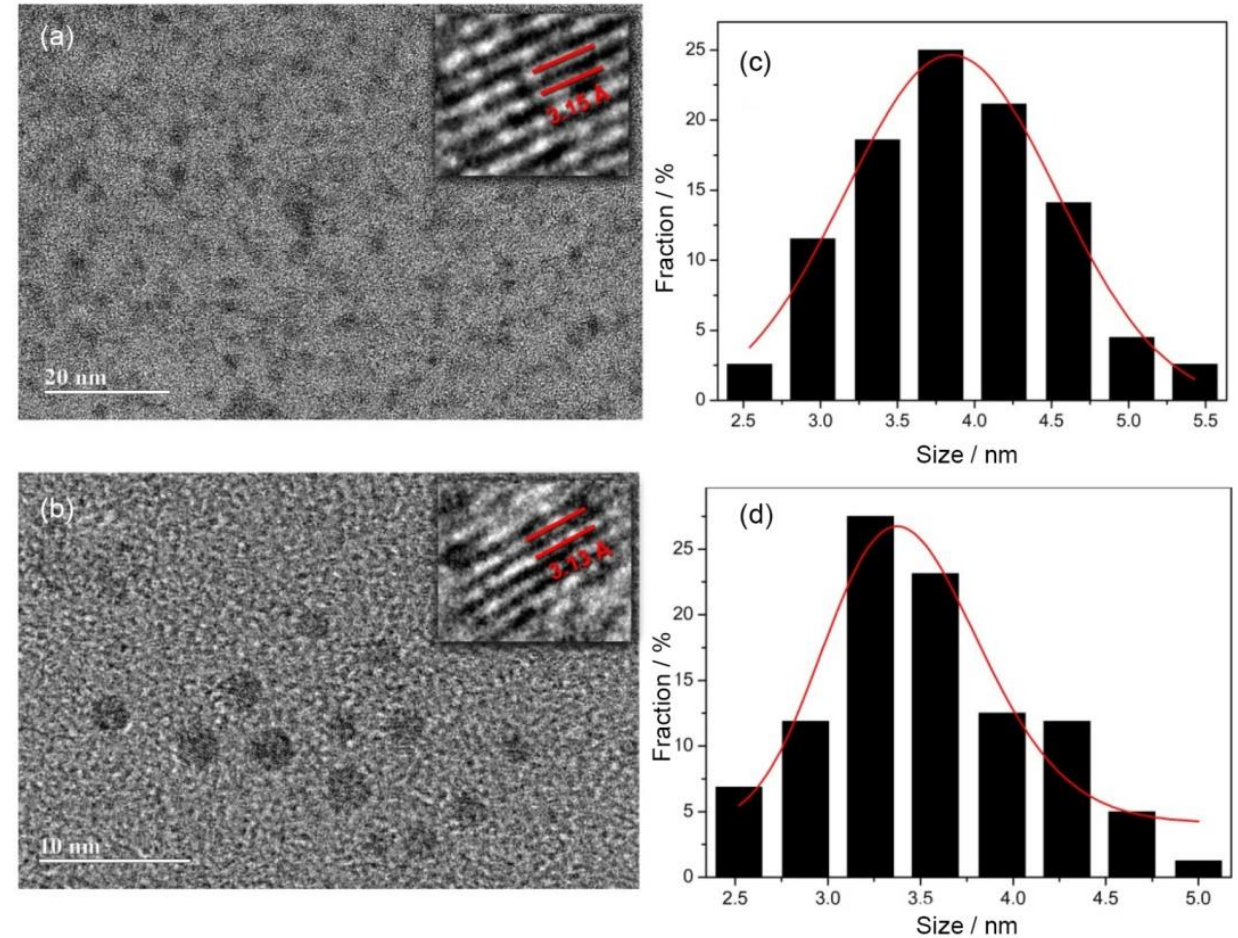

Figure 1. High-resolution transmission electron microscopy (HRTEM) images of C-dots (a) $\mathbf{1}$ and (b) $\mathbf{2}$; and size distribution histograms for (c) $\mathbf{1}$ and (d) 2. The inserts in (a) and (b) emphasize the lattice fringes of representative particles.

from C-dots $\mathbf{1}$ at room temperature (r.t.) is available in the Supporting Information (Figure S2). C-dots 2 exhibited an identical profile. The peaks around 724 and $1068 \mathrm{~cm}^{-1}$ correspond to the $\mathrm{A}_{\mathrm{lg}}$ and $\mathrm{E}_{\mathrm{g}}$ modes of the crystalline sodium nitrate, respectively. ${ }^{17}$ The other two peaks (1380 and $1577 \mathrm{~cm}^{-1}$ ) are generally observed in graphite-based materials. The D band $\left(1380 \mathrm{~cm}^{-1}\right)$ exhibits disorder characteristic related to the presence of $\mathrm{sp}^{3}$ defects, while the peak around $1577 \mathrm{~cm}^{-1}$ is attributed to the well-graphitized carbon, which is associated to inplane vibration of $\mathrm{sp}^{2}$ carbon atoms in the $2 \mathrm{D}$ hexagonal lattice. Thus, the relative intensity ratio of the D-band and $\mathrm{G}-$ band $\left(\mathrm{I}_{\mathrm{D}} / \mathrm{I}_{\mathrm{G}}\right)$ provides the degree of disorder, which makes it possible to compare the structural order between crystalline and amorphous graphitic systems. ${ }^{18,19}$ The $\mathrm{I}_{\mathrm{D}} / \mathrm{I}_{\mathrm{G}}$ for the C-dots synthesized in this work was around 0.95 , demonstrating that they present a similar graphitic-like structure. Results from Raman experiments proved to be in agreement with those reported for C-dots synthesized from unconventional carbon sources..$^{5,20,21}$

The remarkable optical properties of the C-dots $\mathbf{1}$ and 2 were confirmed with ultraviolet-visible spectroscopy (UV-Vis) and photoluminescence spectra. The UV-Vis absorption spectra, exhibited in Figure 2, display an intense band at $228 \mathrm{~nm}$, which may be correlated to $n-\pi^{*}$ transitions. Additionally, low intensity absorption shoulders were observed at about $305 \mathrm{~nm}$, assigned to $\pi-\pi^{\prime \prime}$ functional group at the surface. The difference in the oxidation degree of C-dots does not alter their absorption profile, thus the energy associated with exciton formation in $\mathbf{1}$ and $\mathbf{2}$ are quite similar. The optical band gap, obtained from Tauc and Abeles $^{22}$ method, was the same for both materials $(5.2 \mathrm{eV})$. The origin of the optical properties of C-dots is still hotly debated and is yet not well understood. Therefore, mechanisms involving quantum confinement, surface traps, formation of aromatic structures and recombination of excitons have been proposed. ${ }^{3}$ The emission spectra of $\mathbf{1}$ and 2 measured at r.t. are also shown in Figure 2 and display broad bands centered at 460 and $440 \mathrm{~nm}$, respectively.

In Figure 3 is depicted both the emission spectra and the emission intensities as functions of the temperature and $\mathrm{pH}$. C-dots $\mathbf{1}$ and $\mathbf{2}$ showed an excitation dependence profile with slightly different spectral behavior. C-dots type 1 exhibited a blue shift of $20 \mathrm{~nm}$ (460 to $440 \mathrm{~nm}$ ) when gradually excited from 300 to $340 \mathrm{~nm}$, whereas between $350-450 \mathrm{~nm}$ the emission bands were progressively red shifted by $66 \mathrm{~nm}$ ( 440 to $506 \mathrm{~nm}$ ). On the other hand, the excitation-dependence of $\mathbf{2}$ just starts upon excitation at $350 \mathrm{~nm}$, when the emission bands were shifted about $70 \mathrm{~nm}$ toward the red spectral range. These results are consistent with the presence of defects at the C-dots surfaces as the net result of distinct oxidation degrees. ${ }^{10,23}$ 


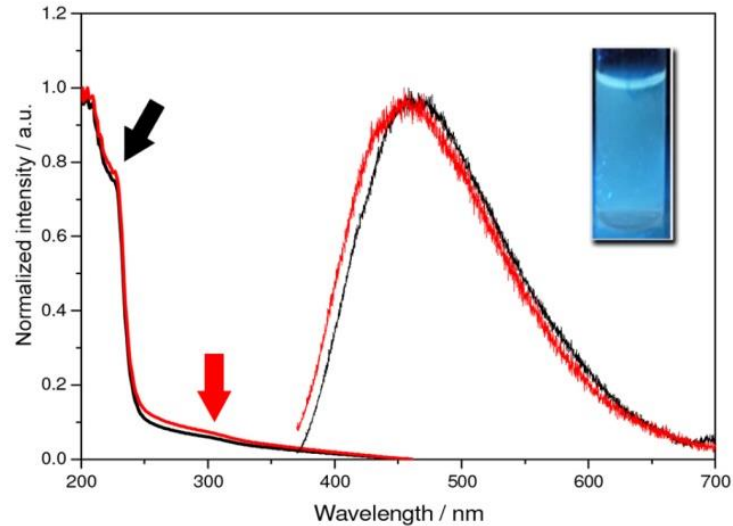

Figure 2. Ultraviolet-visible spectroscopy (UV-Vis) absorption and emission spectra of the C-dots. The solid colored and black lines represent $\mathbf{1}$ and $\mathbf{2}$, respectively. The emission spectra were acquired at r.t. under excitation at $300 \mathrm{~nm}$. Black and colored arrows indicate the $\mathrm{n}-\pi^{*}$ and $\pi-\pi^{*}$ transitions, respectively. The insert shows 1 under UV light-irradiation (366 nm).
C-dots 1 and 2 show distinct spectral behavior with gradual increasing $\mathrm{pH}$ (Figures $2 \mathrm{~b}$ and $2 \mathrm{e}$ ). For C-dots type 2 , the $\mathrm{pH}$ of aqueous media does not dramatically affects their emission, that is, a fact explained by the low $\mathrm{pH}$-dependence of the functional groups at the C-dots surfaces. On the other hand, the photoluminescence intensity of $\mathbf{1}$ decreases when the $\mathrm{pH}$ values increase and may be justified by the presence of large quantities of carboxylic acid groups on the nanoparticle surface. Under acidic conditions, these functional groups are protonated; and with gradual $\mathrm{pH}$ increasing, the Fermi levels can be shifted due to the deprotonation process. ${ }^{24,25}$ The temperature effect on the emission intensities of the C-dots are shown in Figures $3 \mathrm{c}$ and $3 \mathrm{f}$. The emission intensities of $\mathbf{1}$ and $\mathbf{2}$ are progressively diminished as a consequence of multiphoton coupling at higher temperatures, which favors non-radioactive decay.
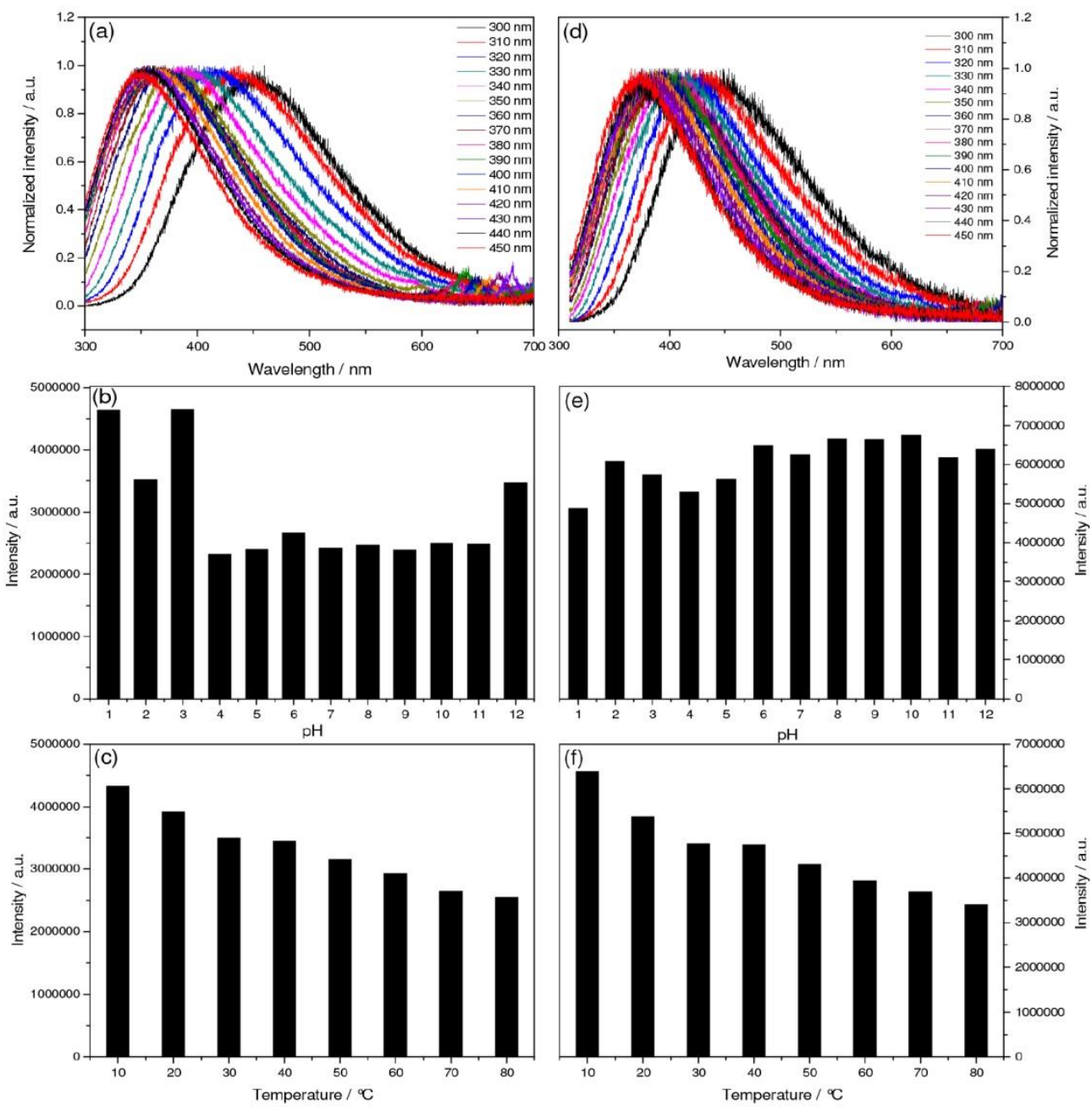

Figure 3. Emission spectra of (a) 1 and (d) 2 acquired at r.t. upon progressive excitation wavelength (from $300 \mathrm{~nm}$ to $450 \mathrm{~nm}$ ); emission intensities as function of $\mathrm{pH}$ of (b) 1 and (e) $\mathbf{2}$ acquired upon excitation at $300 \mathrm{~nm}$; and intensities as a function of the temperature of the analyses for (c) 1 and (f) 2 . 

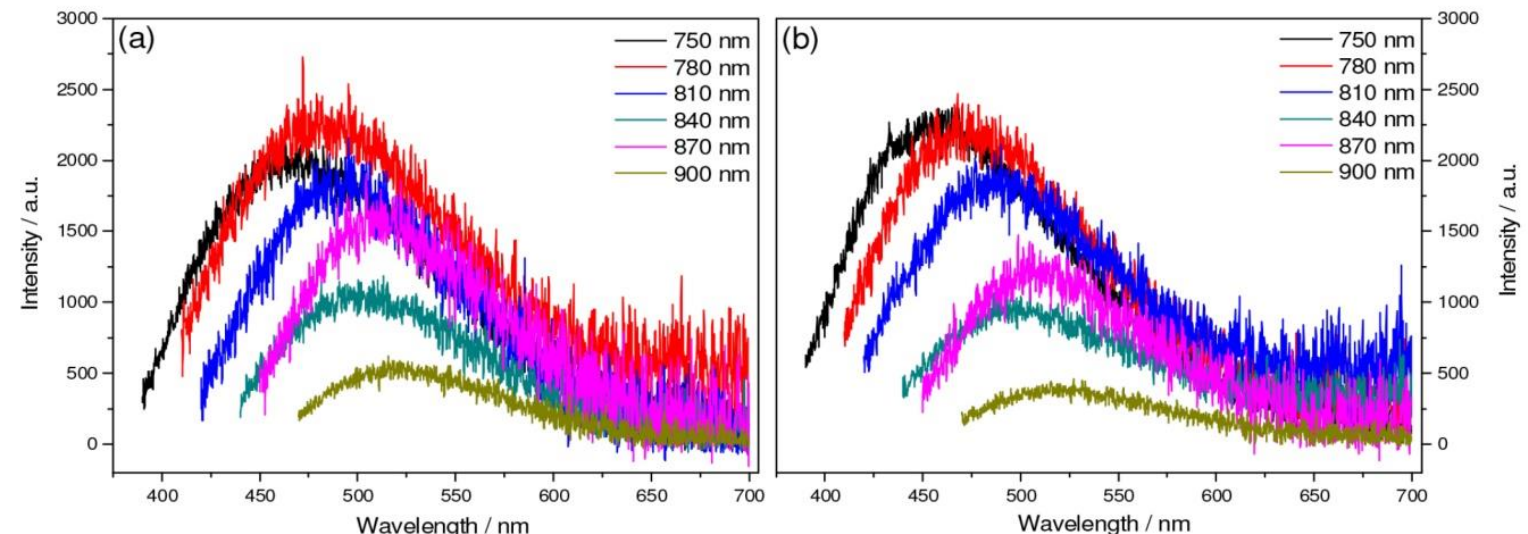

Figure 4. Room temperature up-conversion photoluminescence for (a) $\mathbf{1}$ and (b) $\mathbf{2}$ in aqueous media, under pH 6 upon progressive excitation from 750 to $900 \mathrm{~nm}$

C-dots 1 and $\mathbf{2}$ also exhibited an interesting upconversion (UC) photoluminescent emission when excited in the near-infrared (NIR) region, similar to those reported for $\mathrm{C}$-dots from several carbon sources. ${ }^{26-29}$ The excitation spectra of $\mathbf{1}$ and $\mathbf{2}$ in the NIR region have been acquired monitoring their emission at $460 \mathrm{~nm}$ (Figure S3) and displayed two bands centered at 810 and $850 \mathrm{~nm}$, that is, the bands likely to be responsible for the excitation of the materials. Figure 4 displays the UC emission spectra of $\mathbf{1}$ and $\mathbf{2}$ acquired at r.t. upon excitation at the NIR region.

The UC emission spectra of $\mathbf{1}$ and $\mathbf{2}$ show broad bands centered at 470 and $460 \mathrm{~nm}$ when excited at $750 \mathrm{~nm}$. The UC properties may be justified by the combination of two or more low energy photons to produce the emission of a high energy photon. The UC emission spectra still show an excitation dependence behavior, similarly to those previously reported. ${ }^{25}$ These results show the potential of these nanomaterials for the development and application of new photocatalyst composites, solar cells, and for applications in cell-imaging with two-photon fluorescence microscopy.

Finally, the more oxidized C-dots $\mathbf{1}$ were submitted to cell-imaging experiments. $\mathbf{1}$ has been selected for cellimaging experiments instead of $\mathbf{2}$ for a better comparison with previously reported bioimaging experiments reported elsewhere. ${ }^{4}$ Figure 5 exhibits the confocal images using breast cancer cells (MCF-7).

A cell cytoplasm staining pattern typical of a nonselective bioprobe was observed for both samples (adhered and live cells). It was also observed a very interesting feature when the cell nuclei were analyzed. C-dots $\mathbf{1}$ proved to be capable of staining nucleoli selectively, as is shown for the live cell samples. Although the nucleoli staining pattern was very clear with a large bright green emission (Figures 5a and 5d), live and adhered samples also showed a slight staining pattern associated with the cytoplasm region near the nuclei. These characteristics have already
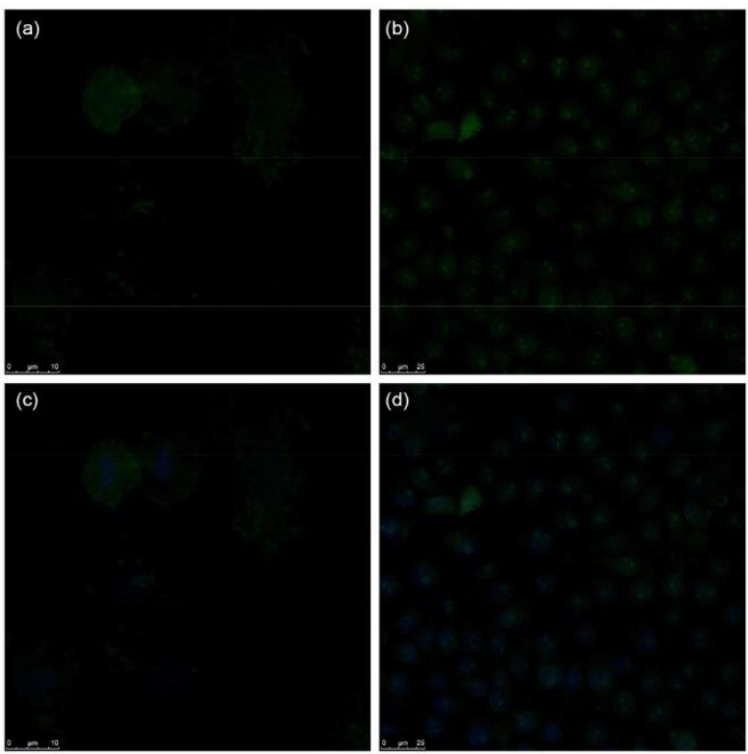

Figure 5. Bioimaging experiments using C-dots type 1 with MCF-7 breas cancer cells. (a) and (b) show the staining patterns (green) for fixed and live cells, respectively; (c) and (d) exhibit overlay between C-dot type 1 and the DNA staining with 4',6-diamidino-2-phenylindole (DAPI). The fluorescent signal is strongly associated with the nucleoli region in live cell samples. C-dots and DAPI are responsible for the green (lighter in printed version) and blue (darker in printed version) emission, respectively. Reference bars: $10 \mu \mathrm{m}$ to (a) and (c), and $25 \mu \mathrm{m}$ to (b) and (d).

been described to similar materials reported by Kang and co-workers. ${ }^{30}$

\section{Conclusions}

In summary, residues from the brewing industry were successfully used as a carbon source to obtain luminescent C-dots through two facile synthetic procedures. C-dots presented excellent aqueous solubility and similar optical properties. The $\mathrm{pH}$ - and temperature-dependence observed for $\mathbf{1}$ and $\mathbf{2}$ may be justified by their distinct oxidation 
degrees. The C-dots type $\mathbf{1}$ were tested as a new bioprobe for bioimaging using MCF-7 cancer cells and proved to be more accumulated in the nucleoli region in live cellimaging experiments. Nucleoli are very activity regions inside the nuclei, which contain several enzyme complexes and play key roles in cellular homeostasis. There are very few molecules commercially available capable of staining nucleoli selectively. The UC photoluminescence exhibited by $\mathrm{C}$-dots and their staining pattern enables their future applications in cell-imagining experiments and provide a new tool to nucleoli studies linked with health and disease conditions through fluorescence microscopy. Bioimaging experiments comparing $\mathbf{1}$ and $\mathbf{2}$ are under way and will be disclosed elsewhere.

\section{Supplementary Information}

Synthetic procedures and additional experimental details are available free of charge at http://jbcs.sbq.org.br.

\section{Acknowledgements}

The authors gratefully acknowledge National Council for Scientific and Technological Development (CNPq), Coordination for the Improvement of Higher Education Personnel (CAPES), Foundation for Scientific and Technological Enterprises (FINATEC), Deanery of Research and Post-Graduation from the University of Brasilia (DPP-UnB), National Institute of Science and Technology (INCT)-Transcend group and Support Research of the Federal District Foundation (FAP-DF) for partial financial support.

\section{References}

1. Jun, S. S.; Xia, B.; Bok, L. S.; Drug Discovery Today 2007, 12, 657.

2. Chan, W. C. W.; Maxwell, D. J.; Gao, X.; Bailey, R. E.; Han, M.; Nie, S.; Curr. Opin. Biotechnol. 2002, 13, 40.

3. Hong, G.; Diao, S.; Antaris, A. L.; Dai, H.; Chem. Rev. 2015, DOI: 10.1021/acs.chemrev.5b00008.

4. Luo, P. G.; Yang, F.; Yang, S. T.; Sonkar, S. K.; Yang, L.; Broglie, J. J.; Liu, Y.; Sun, Y. P.; RSC Adv. 2014, 4, 10791.

5. Zhou, J.; Sheng, Z.; Han, H.; Zou, M.; Li, C.; Mater. Lett. 2012, $66,222$.

6. Liu, S.-S.; Wang, C.-F.; Li, C.-X.; Wang, J.; Mao, L.-H.; Chen, S.; J. Mater. Chem. C 2014, 2, 6477.

7. D’Angelis, E. S. B.; Corrêa, J. R.; Medeiros, G. A.; Barreto, G.; Magalhães, K. G.; de Oliveira, A. L.; Spencer, J.; Rodrigues, M. O.; Neto, B. A. D.; Chem. - Eur. J. 2015, 21, 5055.

8. Mello, L. R. P. F.; Mali, S.; Ind. Crops Prod. 2014, 55, 187.
9. Mardegan, S. F.; Andrade, T. M. M.; Sousa Neto, E. R.; Vasconcelos, E. B. C.; Martins, L. F. B.; Mendonça, T. G.; Martinelli, L. A.; J. Food Compos. Anal. 2013, 29, 52.

10. Bao, L.; Zhang, Z.-L.; Tian, Z.-Q.; Zhang, L.; Liu, C.; Lin, Y.; Qi, B.; Pang, D.-W.; Adv. Mater. 2011, 23, 5801.

11. Zhu, S.; Zhang, J.; Liu, X.; Li, B.; Wang, X.; Tang, S.; Meng, Q.; Li, Y.; Shi, C.; Hu, R.; RSC Adv. 2012, 2, 2717.

12. Wu, L.; Luderer, M.; Yang, X.; Swain, C.; Zhang, H.; Nelson, K.; Stacy, A. J.; Shen, B.; Lanza, G. M.; Pan, D.; Theranostics 2013, 3,677 .

13. Lotya, M.; Hernandez, Y.; King, P. J.; Smith, R. J.; Nicolosi, V.; Karlsson, L. S.; Blighe, F. M.; De, S.; Wang, Z.; McGovern, I.; J. Am. Chem. Soc. 2009, 131, 3611 .

14. Krishnamoorthy, K.; Veerapandian, M.; Yun, K.; Kim, S.-J.; Carbon 2013, 53, 38.

15. Wang, G.; Yang, J.; Park, J.; Gou, X.; Wang, B.; Liu, H.; Yao, J.; J. Phys. Chem. C 2008, 112, 8192.

16. Yadav, R. M.; Dobal, P. S.; Shripathi, T.; Katiyar, R. S.; Srivastava, O. N.; Nanoscale 2009, 4, 197.

17. Rousseau, D. L.; Miller, R. E.; Leroi, G. E.; J. Chem. Phys. 1968, 48, 3409.

18. Wu, M.; Wang, Y.; Wu, W.; Hu, C.; Wang, X.; Zheng, J.; Li, Z.; Jiang, B.; Qiu, J.; Carbon 2014, 78, 480.

19. Bagga, K.; McCann, R.; Wang, M.; Stalcup, A.; Vazquez, M.; Brabazon, D.; J. Colloid Interface Sci. 2015, 447, 263.

20. Hsu, P.-C.; Chang, H.-T.; Chem. Commun. (Cambridge, U. K.) 2012, 48, 3984.

21. Hsu, P.; Shih, Z.; Lee, C.; Chang, H.; Green Chem. 2012, 14, 917.

22. Tauc, J. In Optical Properties of Solids; Abeles, F., ed.; American Elsevier: New York, 1972, ch. 5.

23. Zhu, S.; Zhang, J.; Tang, S.; Qiao, C.; Wang, L.; Wang, H.; Liu, X.; Li, B.; Li, Y.; Yu, W.; Adv. Funct. Mater. 2012, 22, 4732.

24. Zhao, W.; Song, C.; Pehrsson, P. E.; J. Am. Chem. Soc. 2002, 124, 12418.

25. Jia, X.; Li, J.; Wang, E.; Nanoscale 2012, 4, 5572.

26. Cao, L.; Wang, X.; Meziani, M.; Lu, F.; Wang, H.; Luo, P.; Lin, Y.; Harruff, B.; Veca, L.; Murray, D.; J. Am. Chem. Soc. 2007, 129, 11318.

27. Li, H.; He, X.; Kang, Z.; Huang, H.; Liu, Y.; Liu, J.; Lian, S.; Tsang, C. H. A.; Yang, X.; Lee, S. T.; Angew. Chem., Int. Ed. 2010, 49, 4430.

28. Zhuo, S.; Shao, M.; Lee, S.; ACS Nano 2012, 6, 1059.

29. Yin, B.; Deng, J.; Peng, X.; Long, Q.; Zhao, J.; Lu, Q.; Chen, Q.; Li, H.; Tang, H.; Zhang, Y.; Analyst (Cambridge, U. K.) 2013, 138,6551 .

30. Kong, W.; Liu, R.; Li, H.; Liu, J.; Huang, H.; Liu, Y.; Kang, Z.; J. Mater. Chem. B 2014, 2, 5077.

Submitted: July 16, 2015

Published onlien: October 30, 2015 